\title{
A Multi-Stage Under-Voltage Load Shedding Scheme using a DIgSILENT power factory software to stabilize the power system network
}

\author{
Mkhululi Elvis Siyanda Mnguni ${ }^{1}$ \\ ${ }^{1}$ Researcher/Lecturer, Electrical, Electronic, and Computer Engineering Department, \\ Cape Peninsula University Of Technology, Bellville Campus, P.O Box 7530, South Africa.
}

\begin{abstract}
The electrical power system environment is based on generation, transmission and distribution. The best practice of the power system is that the generation plant must always be far from the consumers (load demand). The practice created a space where the power needs to be transmitted and distributed to the consumers. During this process, it is critical and important to keep the supply to the consumers at all times. Since the power systems are exposed to all vast condition, it is exposed to a dangerous environment. On the other hand, the load demand is continuously increasing and this can lead to power system instability. The objective of electrical engineers is to protect the power system and maintain stability. One of the best indicators that are used to monitor power system activities is the voltage. When power generation is not able to meet the load demand the system becomes unstable and this has become a concern last two decades. The paper presents Under-Voltage Load Shedding (UVLS) scheme is implemented in a multi-area power system network. The voltage studies are provided to get information and knowledge on how to develop an ideal under-voltage load shedding scheme. The objectives of the paper are to assist with deciding on the security of the system under the various conditions that can lead to power system stability. The objectives are mitigated by developing and implementing a multistage UVLS scheme for power utilities. The new proposed scheme is based on soft Intelligent Electronic Devices (IEDs). The proposed technique makes use of the DIgSILENT power factory platform where the whole system is modeled for simulations. A comprehensive case study is presented to analyze problems that are formed by voltage instability. The paper gives answers to questions such as: How and why does instability occur? What are the parameters or what are the main reasons for voltage instability? What are the key factors contributing to voltage instability? What are the voltage weak areas? What measures are most effective in improving voltage stability? based on the fundamental dependencies between the voltage, power, and current in power networks with loads. It also elaborates on the effect of power system instability when exposed to some contingency. The power flow study is deployed to determine the optimal system operating conditions of the IEEE39 bus system. Methods such as the PV curve and QV curve are applied in the paper to find the critical operation point before the voltage instability occurs in the power system. Five case studies were implemented where the proposed algorithm uses the Intelligent Electronic Devices ( IED) to implement the Under Voltage Load Shedding (UVLS) scheme wherein a case the voltage elements are used for voltage monitoring. The developments in this paper
\end{abstract}

extended the capability of the DIgSILENT power factory software to be used for more advanced power stabilities studies

Keywords: Power system, Load shedding scheme, Intelligent Electronic Devices (IEDs), Under voltage load shedding scheme, DIgSILENT Power factory software

\section{INTRODUCTION}

The power system network is divided into three subsystems. These subsystems are coordinated according to their voltage levels known as high voltage (HV), medium voltage (MV), and low voltage (LV). In most cases, these subsystems are interconnected to develop a complete power system network. The priority of the power system network is transmitting power from the sending side to the receiving side with minimum losses. The interconnections of the power network and the changes due to the discrepancy of loads and disturbances ending up to power system instability. It has been reported that blackout problems in recent years relate to voltage collapsing due to voltage stability in the network system. Generally, voltage problems are developed through a sequence of unwanted events. When these events are not attended they cascade and eventually create voltage instability that leads to unacceptable conditions in the power network [1], [2].

The problems associated with load shedding schemes have been under study for decades. However, research shows that there is still a need to develop a better solution that can be innovative. In most cases, power system utilities use load shedding as the last resort to control the system during emergencies. This concept needs to be changed because it in some cases it needs to be coordinated with the other protection schemes that the power system is using.

Due to the increased growth of the economy over the years the interconnectivity of power systems increase led to the complexity of stability issues. In the 1970s and 1980s, stability problems were experienced. As a result, dynamic simulation programs were developed to assist in their analysis [3], [4], [5]. Later the Institute of Electrical and Electronics Engineers (IEEE) working group developed guidelines to enhance the characteristics of the power plant when there are major disturbances. In the late nineties, the power system engineers focused on special study techniques such as modal analysis using eigenvalue concepts. They later used supplementary control of generator excitation system, Static Var 
International Journal of Engineering Research and Technology. ISSN 0974-3154, Volume 13, Number 6 (2020), pp. 1475-1492

(C) International Research Publication House. https://dx.doi.org/10.37624/IJERT/13.6.2020.1475-1492

Compensators (SVCs), and High Voltage Direct Current (HVDC) converters to solve system oscillation problems [6], [7]. One of the local example improving power system stability was the demonstration on the Eskom network using the strategic placement of the HVDC links [8]. Powerful simulation programs have been developed to date, that is capable of modeling large complex systems using detailed device models. Over the last century, the electric power system has been involved in different forms of instability problems. The computational tools have been used to analyze the stability of power systems. The history review shows that making use of these developed computational tools provides a better understanding of the system stability for the electrical power industry

In the past, different approaches have been used to achieve load shedding schemes in various power utilities The following is a brief description of algorithms that were proposed from previous researchers.

[9] presented a new approach to the load shedding program to guarantee correct electrical system operation by increasing the number of participants. The new load control strategy was named Distributed Interruptible Load Shedding (DILS). It was based on controlling load individually. [10] proposed a Power Transfer Stability Index (PTSI) algorithm that was based on Fixed Shed Fixed Delay (FSFD) and Variable Shed Variable Delay (VSVD) approaches to avoid voltage collapse. A Power System Analysis Toolbox was used for simulations. [11] presented the application of a redundant load shedding system for islanded power plants. Their objectives were to maintain the power system stability and process survivability for major system faults under a variety of system configuration topologies. [12] used a Fast Voltages Stability Index (FVSI) method assisted by a Photovoltaic (PV) analysis algorithm for numerical verification of the locations where the loads need to be shed in the power system. A Power System Simulation for Engineers (PSSE) simulation software was used for modeling. The constraints of this method are that the researcher focused only on the static behavior of the system and did not look at the dynamic behavior

[13] Applied a voltage stability index approach to indicate the load condition for the under-voltage load shedding (UVLS) scheme. A mathematically based Fast Voltage Stability Index (FVSI) algorithm was used. The considered system was the 30 bus system with 27 lumped loads, a mini-hydro generator, and a PV DG. The software used was PSCAD.

In [15] a centralized adaptive wide-area load shedding scheme that was incorporated into power system real-time limitations was proposed. The developed algorithm has three stages. The first stage determines the requirements needed for implementation. The second stage specifies the optimal amount and location of the load to drop and posts load shedding strategies. It also accommodates all operational limits and considers the interruption cost for the shed loads. The third stage determines the event type in real-time. A fuzzy decisionmaking method based on measurements, gathered from the power network was developed. An IEEE 39 Bus system was used to conduct the study
In [16] a Fault-induced delayed voltage recovery (FIDVR) algorithm that is relay-based under-voltage load shedding (UVLS) scheme was proposed. The authors looked at the planning concerns and design criteria for the UVLS which were later followed by implementation details of the relay operation logic programs. The program used was based on a standard microprocessor-based multi-functional relay. The proposed algorithm was validated using dynamic simulations, which were performed using PSS/E program. Recovery time calculations using various voltage samples were performed.

A conventional UVLS executed by the protective relays was introduced in [17] using a Voltage Stability (VS) violation algorithm based on decentralized configurations. The relays were configured to operate at fixed time delay and threshold voltage. This method led to unnecessary load shedding and the system experienced overvoltage.

In [18] a load shedding scheme based on voltage instability index to prevent voltage collapse was presented. The algorithm used PMUs, Jacobian matrix, and V-Q sensitivity calculation. The simulation was based on the Modified 4 bus system consisting of two areas. DIgSILENT Power factory software was used as the platform for the simulation. The drawback of the paper is that the algorithm developed was validated using simulation and no real-time implementation was done.

A new load shedding scheme based on the algorithm of time to voltage collapse was proposed in [19]. A decentralized method of load shedding using voltage relays was used for an IEEE 30 Bus system. The settings and communication between the relays were not specified. The developed scheme was not practically implemented.

A new event-driven emergency load-shedding scheme is presented in [20]. An Optimal Event-Driven Load-Shedding (OEDLS) model was developed. The algorithm was based on linearizing the nonlinear OEDLS model through trajectory sensitivity. A parallel computation scheme to accelerate the problem-solving process is used. The proposed algorithm was tested and validated using Computing Toolbox in MATLAB and the PSS/E software

In [21] a new under-impedance load shedding (UILS) scheme was presented. The proposed method used a quadratic distance relay. The concept was based on the trajectory of load impedance monitored by the proposed UILS relay. The new under-impedance load shedding scheme was tested on various networks, including a real power system model. Based on the results UILS was proving to operate efficiently.

Three different load shedding schemes - voltage-based, timerbased, and combined, used in direct current (DC) microgrid were compared in [22] using the PSCAD/EMTDC software. The results show that the voltage-based and timer-based load shedding schemes drop the bus voltages lower than the limits. The timer-based load shedding caused over shedding of loads. This degraded the power supply reliability. They also discovered that the combined methods increased the power supply reliability to the critical loads and also prevented over 
International Journal of Engineering Research and Technology. ISSN 0974-3154, Volume 13, Number 6 (2020), pp. 1475-1492

(C) International Research Publication House. https://dx.doi.org/10.37624/IJERT/13.6.2020.1475-1492

shedding of loads.

[23] propose a load shedding two-level framework use in a distribution network to prevent voltage from collapsing. The two frame levels were categorized as the lower and upper level, where the lower level consisted of the local load shedding controller. The higher level consists of a controller that coordinates the local controller. This local controller used to reduce the load amount using the sensitivity based piecewise linearization. A Swedish Nordic 32 bus system was used to implement and validate the proposed scheme.

The drawbacks of the current literature in implementing the load shedding schemes are that most researchers focused more on the theory aspect and overlook the simulation and practical implementations. Where on the other hand the power utilities and industry prefer the feasibility study to end up with a practical implementation for testing and validating the results.

The traditional way of validating the theory is to implement simulations that will prove that the proposed scheme is working. The power system network simulations will be based on DIgSILENT power factory software where the Under-Voltage load shedding scheme will be implemented. The advantage of using a DIgSILENT power factory software is the fact it can be compared with the physical equipment, such as protection relays. This will opens a large spectrum of research and apply advanced tests that are required by the power utilities before the scheme is implemented in their power system. The other drawbacks with the current existing under-voltage load shedding scheme are the lack of adaptation, especially towards the disturbances. Another drawback with the current schemes is that they over shed the loads or under shed, the loads and this could lead to power system instability. In most cases, the undervoltage load shedding scheme focuses on one area where this paper will cover cases where under-voltage load shedding is implemented in multi-area power systems.

To attend power system problems, simulation models are an essential part when it comes to power system studies. Therefore, methods and techniques such as a Power- Voltage (PV) curve and a Reactive Power-Voltage $(\mathrm{QV})$ curve are used to run various scenarios of simulation to gain a statistical significance of voltage stability analysis using load flow studies [1].

The under-voltage studies are provided in this paper to get information and knowledge to develop an ideal under-voltage load shedding scheme.

The structure of the paper is presented as follows

A system developed for voltage stability analysis is introduced in part II. Proposed case studies are presented in part III. Case study 1 in part III.4 focuses on developing the PV curve calculations. Case study 2 in part III.5 focuses on the load demand of the individual load in each area when the system is at the critical point. Case study 3 in part III.6 covers the point beyond critical behavior when the power system is overloaded. Case study 4 in part III.7 describes the RMS/EMT Simulation toolbox to monitor the loaded buses and see how they are influenced when the system loads are increased. Case study 5 based on Implementation of the Under Voltage Load shedding (UVLS) scheme in the DIgSILENT Power factory environment is covered in part 111.8. Part IV presents the discussion of the paper and part $\mathrm{V}$ is the conclusion of the paper.

In the past, the Under Voltage Load shedding (UVLS) schemes proposed still have not found a noble solution when it comes to the correct amount of load to be shed during disturbances. The objective of this paper is to develop and implement a multistage UVLS scheme for power utilities. The new proposed scheme is based on soft Intelligent Electronic Devices (IEDs) The proposed technique makes use of the DIgSILENT power factory platform where the whole system is modeled for simulations.

Deliverables of the paper are as follows:

1) A model of the IEEE 39 bus system is developed in the DIgSILENT power factory software environment and load flow simulation is performed.

2) A system for voltage stability analysis.

3) New models of DIgSILENT soft IEDs (protection devices) are used for the development of the IEEE 39 bus system and implementation of the load shedding schemes.

4) A new process of gradually load increase to create load contingency in the DIgSILENT power factory software environment is developed. The issues that lead the power system to instability are investigated and a new load shedding scheme to return the network to stability conditions is developed.

5) New UVLS algorithms based on multi-stage load shedding operation and on prioritization of the amount, order, and location of the loads to be shed are developed in the DIgSILENT power software environment.

6) The soft IEDs are developed to be implemented in the DIgSILENT power factory environment.

7) New multi-stage decision making logic by the IEDs for the decentralized type of load shedding DIgSILENT power factory environment is developed.

8) The performance UVLS scheme of the power systems is investigated and implemented.

\section{A SYSTEM DEVELOPED FOR VOLTAGE STABILITY ANALYSIS}

The instability of voltage in the power systems has become a concern. Various factors influence this problem. The growth in the environment and population has forced the electric utilities to operate their system close to their limits. Due to load demand voltage has also approach instability. The basic solution would be to increase its supply to meet the load demand. Proper planning is required when developing an ideal power system that will be able to supply power efficiently. Power system engineers are required to produce accurate results when it comes to power system studies. A comprehensive case study is presented in this paper to analyze problems that are formed by voltage instability. A systematic procedure of the case study in this paper is done in the following manner:

- Establishment of the base case study

- Developing a credible contingency by using of which the voltage stability is analyzed.

- Defining the main parameters for calculation of system voltage stability margins 
International Journal of Engineering Research and Technology. ISSN 0974-3154, Volume 13, Number 6 (2020), pp. 1475-1492

(C) International Research Publication House. https://dx.doi.org/10.37624/IJERT/13.6.2020.1475-1492

- Specification of the system voltage stability margins from the base case and all the creditable contingency cases

Two features are considered when analyzing voltage stability. The first one is the proximity to voltage instability of the power network. This feature deals with how close the systems are to voltage instability. The second feature is determining the mechanism of voltage instability. This part is determined by the following questions:

- How and why does instability occur?

- What are the parameters or what are the main reasons for voltage instability?

- What are the key factors contributing to voltage instability?

- What are the voltage weak areas?

- What measures are most effective in improving voltage stability?

In a complete system, there may be a certain portion of the system that is more prone to voltage instability, therefore, a correct measure must be taken to make that system strong by either injecting or installing more of reactive power sources. The paper gives answers to the above questions based on the fundamental dependencies between the voltage, power, and current in power networks with loads and developments of the methods in DIgSILENT power factory software implementation for all these fundamental dependencies.

\section{II.1. The establishment of the base case}

A load flow study is a pre-requisite for any studies in power systems. Load flow analysis is also well known as power flow. Power flow analysis is the most fundamental when it comes to power systems simulations. Power flow studies involve calculating the voltage magnitude and angle at each node or busbar of the network as well as its real and reactive power. This paper elaborates on the effect of power system instability when exposed to some contingency and to see how it can modify an existing network in the most economical way to cater to increased demand or additional loads. It also helps to investigate the effect of loss of generation or loss of transmission lines, for example, if a transmission line is out through maintenance or there is a fault. The objectives of the paper are to assist with deciding on the security of the system under the various conditions that can lead to power system stability. The power flow study is used in this paper to determine the optimal system operating conditions of the selected power network. The study is also investigating how to improve voltage stability by applying different methods and techniques.

An IEEE 39 bus system [14] was selected as the case study and analyzed using the DIgSILENT Power Factory software tool. This system consists of 39 buses, 10 generators, 19 loads, 34 lines, and 12 transformers. This network was first presented in 1970 as a base model for power flow analysis and since then it has been used for scientific research and publications for many different research purposes. The network model has the following voltage levels $345 \mathrm{kV}, 138 \mathrm{kV}, 230 \mathrm{kV}$, and $16.5 \mathrm{kV}$ respectively. It is also running at a nominal frequency of $60 \mathrm{~Hz}$.

In this paper, the IEEE 39 bus system is divided into four areas for the research investigations, better understanding and analysis, simplicity, and as well as to establish a base case for voltage stability assessment. The network is divided into 4 interconnected areas, as shown in Figure 1 below

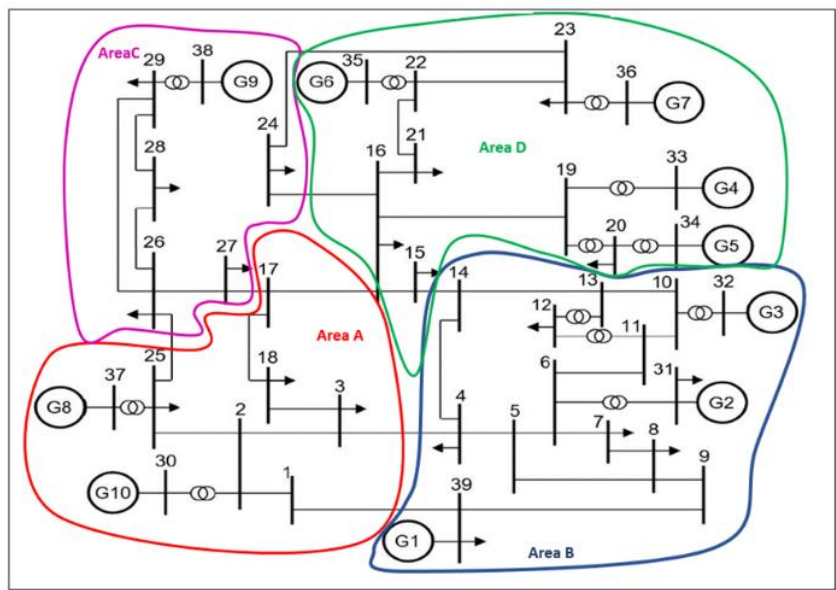

Fig.1: EEE 39 bus system divided into four areas [21]

The DIgSILENT simulations were done to find out the power flow on various transmission lines to monitor the system if it is within the limits of the carrying loading capacity of the transmission lines. It is also used to check if that the voltages at all busbars are within the specified limits. Normally these limits can be plus-minus five percent or ten percent depending on whether the load flow study is done for a high voltage system, the consumer level, or the voltage region.

The base case considers the power system network as a quasistatic one. It is necessary to simulate the network to establish the initial conditions of the busbar voltages and powers. The power flow results are analyzed to identify the weak regions in terms of the real and reactive power balance between the generation and the loads from one side and the values of the busbar voltages from the other. That is the real power injected by the generator has to be equal to the real power drawn by the load and the real power losses in the transmission line. Similarly, the reactive power generated by the generators or the transmission lines must be absorbed by the loads and the losses in the series elements of the transmission lines. The load flow in the DIgSILENT power factory deployed the Newton Raphson method to calculate the power flow of the 39 bus system at the initial condition. The results are shown in Table 1(a) and (b) and Table 2 (a) and (b) below

Table 1a: The loaded bus voltage magnitude for the 39 bus system at the initial condition

\begin{tabular}{|l|l|r|}
\hline Name & $\begin{array}{l}\text { Terminal } \\
\text { Busbar }\end{array}$ & $\begin{array}{l}\text { V, Magnitude } \\
\text { (p.u.) }\end{array}$ \\
\hline Load 03 & Bus 03 & 1.026230286 \\
\hline Load 04 & Bus 04 & 1.005951218 \\
\hline Load 07 & Bus 07 & 1.005792306 \\
\hline Load 08 & Bus 08 & 1.004344768 \\
\hline Load 12 & Bus 12 & 1.004377816 \\
\hline
\end{tabular}


International Journal of Engineering Research and Technology. ISSN 0974-3154, Volume 13, Number 6 (2020), pp. 1475-1492

(C) International Research Publication House. https://dx.doi.org/10.37624/IJERT/13.6.2020.1475-1492

\begin{tabular}{|l|l|r|}
\hline Name & $\begin{array}{l}\text { Terminal } \\
\text { Busbar }\end{array}$ & $\begin{array}{l}\text { V, Magnitude } \\
\text { (p.u.) }\end{array}$ \\
\hline Load 15 & Bus 15 & 1.003107473 \\
\hline Load 16 & Bus 16 & 1.015409795 \\
\hline Load 18 & Bus 18 & 1.021845294 \\
\hline Load 20 & Bus 20 & 0.987893477 \\
\hline Load 21 & Bus 21 & 1.017591391 \\
\hline Load 23 & Bus 23 & 1.028101627 \\
\hline Load 24 & Bus 24 & 1.011715886 \\
\hline Load 25 & Bus 25 & 1.044536881 \\
\hline Load 26 & Bus 26 & 1.044108649 \\
\hline Load 27 & Bus 27 & 1.026762623 \\
\hline Load 28 & Bus 28 & 1.044499196 \\
\hline Load 29 & Bus 29 & 1.049782756 \\
\hline Load 31 & Bus 31 & 0.981999993 \\
\hline Load 39 & Bus 39 & 1.029999971 \\
\hline
\end{tabular}

Table 1b: The total loading powers for the 39 bus system during the initial condition

\begin{tabular}{|c|c|c|c|}
\hline Name & $\begin{array}{l}\text { Active Power } \\
\text { (MW) }\end{array}$ & $\begin{array}{l}\text { Reactive } \\
\text { Power ( Mvar) } \\
\end{array}$ & $\begin{array}{l}\text { Apparent } \\
\text { Power (MVA) }\end{array}$ \\
\hline Load 03 & 322 & 2.400000095 & 322.008944 \\
\hline Load 04 & 500 & 184 & 532.7813811 \\
\hline Load 07 & 233.8000031 & 84 & 248.4319654 \\
\hline Load 08 & 522 & 176 & 550.872036 \\
\hline Load 12 & 7.5 & 88 & 88.319024 \\
\hline Load 15 & 387.7022095 & 153 & 416.799716 \\
\hline Load 16 & 329 & 32.29999924 & 330.5817447 \\
\hline Load 18 & 158 & 30 & 160.8228839 \\
\hline Load 20 & 628 & 103 & 636.3906033 \\
\hline Load 21 & 274 & 115 & 297.1548418 \\
\hline Load 23 & 247.5 & 84.59999847 & 261.5595721 \\
\hline Load 24 & 308.6000061 & 92.19999695 & 322.0788773 \\
\hline Load 25 & 224 & 47.20000076 & 228.9188504 \\
\hline Load 26 & 139 & 17 & 140.0357097 \\
\hline Load 27 & 281 & 75.5 & 290.9660633 \\
\hline Load 28 & 206 & 27.60000038 & 207.8407083 \\
\hline Load 29 & 283.5 & 26.89999962 & 284.7733484 \\
\hline Load 31 & 9.199999809 & 4.599999905 & 10.28591248 \\
\hline Load 39 & 1010 & 340 & 1065.692263 \\
\hline Total & 6070.802218 & 1683.299995 & 6396.314445 \\
\hline
\end{tabular}

The Newton Raphson algorithm manages to converge in 4 iterations successfully. During the initial condition for the base case, it can be seen that the powers of the total loading for all the loads add up to $6070.80 \mathrm{MW}$ for the active power, 1683.29Mvar for the reactive power and 6396.31 MVA for the apparent power. The results also show that the load bus voltages are within the limits and therefore a conclusion was made that the 39 bus system is stable in the initial condition.

Table 2a: The bus voltages where the generators are connected during the initial condition

\begin{tabular}{|l|l|r|}
\hline Name & $\begin{array}{l}\text { Terminal } \\
\text { Busbar }\end{array}$ & $\begin{array}{l}\text { V, Magnitude } \\
\text { p.u. }\end{array}$ \\
\hline G 01 & Bus 39 & 1.029999971 \\
\hline G 02 & Bus 31 & 0.981999993 \\
\hline G 03 & Bus 32 & 0.983099997 \\
\hline G 04 & Bus 33 & 0.997200012 \\
\hline G 05 & Bus 34 & 1.012300015 \\
\hline G 06 & Bus 35 & 1.049299955 \\
\hline G 07 & Bus 36 & 1.039999962 \\
\hline G 08 & Bus 37 & 1.027799964 \\
\hline G 09 & Bus 38 & 1.026499987 \\
\hline G 10 & Bus 30 & 1.047500014 \\
\hline
\end{tabular}

Table 2b: Generated power supply for the 39 bus system during the initial condition

\begin{tabular}{|l|l|l|l|}
\hline Name & $\begin{array}{l}\text { Active Power } \\
\text { MW }\end{array}$ & $\begin{array}{l}\text { Reactive Power } \\
\text { Mvar }\end{array}$ & $\begin{array}{l}\text { Apparent Power } \\
\text { MVA }\end{array}$ \\
\hline G 01 & 1000 & 160.1804292 & 1012.747634 \\
\hline G 02 & 494.9535618 & 266.3805123 & 562.0832729 \\
\hline G 03 & 650 & 187.6580409 & 676.5467761 \\
\hline G 04 & 632 & 149.405342 & 649.4197073 \\
\hline G 05 & 508 & 184.0548481 & 540.3148962 \\
\hline G 06 & 650 & 294.4247395 & 713.5726503 \\
\hline G 07 & 560 & 75.09385166 & 565.0124658 \\
\hline G 08 & 540 & 13.59119483 & 540.1710105 \\
\hline G 09 & 830 & 23.86763963 & 830.3431003 \\
\hline G 10 & 250 & 157.6510995 & 295.5568798 \\
\hline Total & 6114.953562 & $\mathbf{1 5 1 2 . 3 0 7 6 9 8}$ & $\mathbf{6 3 8 5 . 7 6 8 3 9 3}$ \\
\hline
\end{tabular}

Tables $2 \mathrm{a}$ and $2 \mathrm{~b}$ represent the results for the power supply from all 10 generators of the 39 bus system at the initial condition. It can be seen that the total supply of active power is $6114.95 \mathrm{MW}$, reactive power is $1512.31 \mathrm{Mvar}$ and apparent power is 6385.76 MVA respectively. When the results from Tables $1 \mathrm{a}$ and $1 \mathrm{~b}$ were compared with these of Tables $2 a$ and $2 b$, it was discovered that the system is balanced because the generation power meets the load demand and all the bus terminals are within the limits. Therefore, the whole system is stable during the initial conditions with the above. the base case was established for the 39 bus system and the next part was to develop credible contingencies through which the voltage stability of the system is analyzed.

\section{II.2. PV curve application}

Voltage stability is determined using a power flow simulation and to investigate different case studies to analyze voltage stability. The power flow study determined the maximum transfer of power that is bounded by the power system network 
International Journal of Engineering Research and Technology. ISSN 0974-3154, Volume 13, Number 6 (2020), pp. 1475-1492

(C) International Research Publication House. https://dx.doi.org/10.37624/IJERT/13.6.2020.1475-1492

laws. The methods such as the PV curve and QV curve are applied in the paper to find the critical operation point before the voltage instability occurs in the power system. A PV curve determines the transfer limits which are accountable for the voltage and active power flow functions.

The PV curve operates in such a manner that when the active load power transfer is increased, the voltage at some buses decreases. As the power transfer capacity increases the voltage at the buses decreases until it reaches the low voltage criterion known as the low voltage transfer limit. Based on the grid code in power system stability the lower voltage-transfer limit is five percent less than its initial magnitude. In a case of the per-unit system, the low voltage transfer limit is represented as $0.95 \mathrm{pu}$ and the upper voltage-transfer limit is five percent more than the initial magnitudes, which is represented as $1.05 \mathrm{pu}$. The power transfer capacity can continue to increase until the voltage collapse condition is reached, and this point is known as the voltage collapse transfer limit. Figure 2 below elaborates on the relationship between the receiving end voltage which is at the loaded bus and the load power transferred as an increase of the active power. The relationship between these components develops a PV curve characteristic.

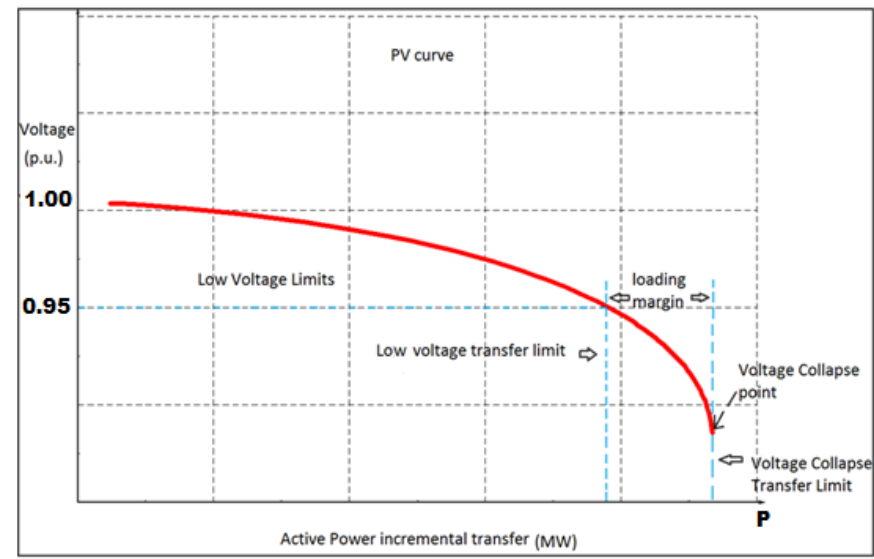

Fig. 2. The developed PV curve characteristic

At the point below the low voltage transfer limit also known as the knee point of the curve, a voltage instability of the system will start to occur and the voltage drops rapidly with an increase in the transfer power flow. A Load flow solution is used in this paper to indicate the voltage instability at all the loaded buses in the system. The load flow is systematically operated at or near the stability limit to perform a voltage stability analysis so that a satisfactory operating condition is met to prevent voltage collapse. PV curves are a useful tool for setting the performance of a network under conditions of increased loads indicating how much the demand can be scaled and what is the critical point in the network.

The method used in this simulation is based on calculating the PV curve which is developed through manipulation of the power transfer to the loads with defined step size increment for a series of AC load flow calculations while the bus voltages, generator outputs and the branch flows of the system are monitored.

\section{II.3. QV curve application}

As explained earlier the PV curve analysis, is based on the effect of active power flow on voltage instability. However, it has been observed that the power factor of the loads has a significant impact on the overall system behavior since the voltage drop in the line is based on both active and reactive power transfer. Therefore, the $\mathrm{QV}$ curve is also required to analyze the voltage stability of the system as well. QV curves are used to define the reactive power injection required at a bus to return the bus voltage to the required value. The QV curve is built or drawn through a series of AC load flow calculations by first looking at the existing reactive loading at a bus. The voltage at the bus can be calculated by applying a succession of load flow simulations. The concept is based on increasing the reactive load in incremental steps until the power flow experiences convergence difficulties. At this point, the system approaches the voltage collapse point. Figure 3 represents a typical QV curve that is generated for a system that is stable at moderate loading and unstable at higher loadings.

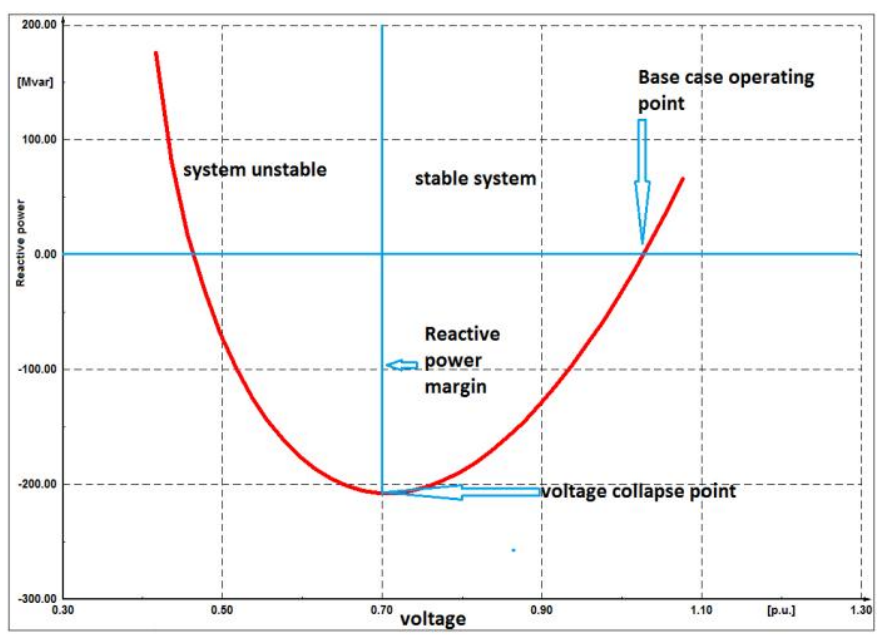

Fig.3: The developed QV curve characteristic

The voltage stability limits for the QV curve are presented at the bottom of the graph where the change of the reactive power $\mathrm{Q}$ concerning voltage, $\mathrm{V}$ is equal to zero. The end of the curve at the bottom also defines the minimum reactive power required to be injected to keep the system as stable operation. When the system is operating in the stable condition it is represented on the right side of the QV curve and when the system is at the unstable condition it is represented on the left side of the QV curve.

\section{PROPOSED CASE STUDIES}

In logical concepts, the power flow simulation provides information for the base case of the study, and then the Voltage Stability Margin (VSM) for the system is required to perform the voltage stability analysis. Contingency analysis is implemented to identify the limitation of the power system under study. Two factors were considered when defining the VSM of the network under study. These factors are as follow:

Performance levels of the power network components

Disturbance (load-ability) Simulations 
International Journal of Engineering Research and Technology. ISSN 0974-3154, Volume 13, Number 6 (2020), pp. 1475-1492

(C) International Research Publication House. https://dx.doi.org/10.37624/IJERT/13.6.2020.1475-1492

\section{III.1. The performance levels}

The network under study consists of various components, and they have different levels of requirements. The components such as generators, lines, transformers, buses have different performance levels that are defined by specific minimum requirements. These requirements are specified in terms of minimum real or reactive power margins which are categorized in Table 3 shown below

Table 3: The performance levels

\begin{tabular}{|l|l|}
\hline Level A & $\begin{array}{l}\text { This is the case where any single component in } \\
\text { the power system network is lost or loaded }\end{array}$ \\
\hline Level B & $\begin{array}{l}\text { This is the case where any bus section in the } \\
\text { power system network is lost }\end{array}$ \\
\hline Level C & $\begin{array}{l}\text { This is the case where any combination of two } \\
\text { system elements are simultaneously lost without } \\
\text { any adjustments }\end{array}$ \\
\hline Level D & $\begin{array}{l}\text { This is the case where any combination of three or } \\
\text { more system elements are simultaneously lost } \\
\text { without any adjustments }\end{array}$ \\
\hline
\end{tabular}

The real and reactive power margins are required for all the individual levels. It is also important to have a control and protection system that will block the system from voltage instability. This system should utilize the required schemes to maintain the required VSM.

\section{III.2. The Disturbance simulation}

The PV and QV curves were calculated and used to investigate the power system stability. The base case that is under study for voltage stability was exposed to different contingencies to produce the worst conditions. The different performance levels were used to produce the worst-case condition such as maximum loading or a loss of generator or transmission line for the case study. The method of investigation used is based on a study case where the power system is pushed close to the critical levels but still sufficient to receive data that is an adequate form to run the load flow. The contingency was applied for different levels such as increasing the load's demand and at the same time monitoring the different points in the system until the maximum point of the VSM is reached. Another simulation is done where the QV curve is deployed to monitor how much reactive power is required before the system starts to be unstable The disturbances are simulated to identify the areas where the system is mostly stressed or vulnerable. The major disturbances such as a sudden loss of generations or transmission lines or the weakest bus due to load increase are also investigated. A case study was based on the impact of the severe contingencies where the weakest buses may not necessarily be in the same area where the contingency is located. Therefore, buses from the areas different from the disturbed area are also investigated. When investigating the voltage stability two aspects were taken into consideration. One was to consider the proximity to voltage instability to know how close the system is to voltage instability. The activities of components such as active power flow at the critical point, the reactive power that is recovered, and the load levels are analyzed. All the activities are dependent on the VSM. The second consideration was the mechanism of voltage instability where the focus was on the key factors that influence the voltage instability and assisting with identifying the voltage weak areas. It also identifies what the most effective measures are that can be taken to improve voltage stability where in this case a load shedding schemes are implemented.

\section{III.3. The case studies}

Five case studies were implemented in this paper. The flowchart that represents the performed case studies aims is shown in Figure 4 below.

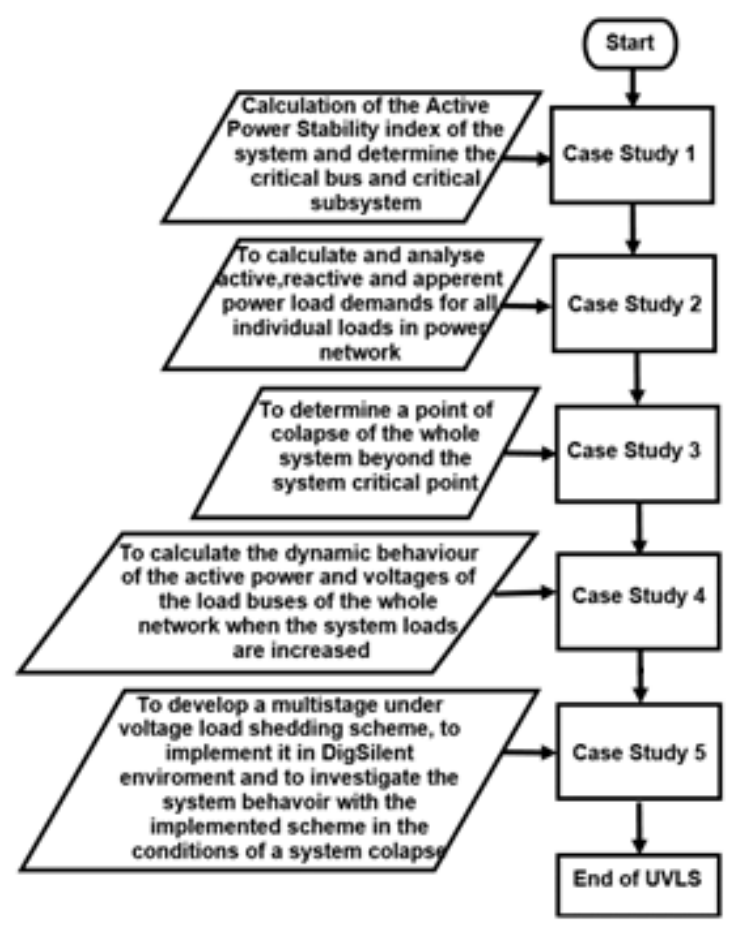

Fig. 4. The flow chart with case studies and their aims

\section{III.4. Case study 1}

The aim of case study 1 was to used the PV curve to calculate the voltages at the buses concerning the active power of the loads. A PV curve is built and analyzed to develop the Power Margin (PM) of the whole system. A case study is performed by simulation which included suitable modeling for all events that lead to voltage instability. A normal load flow using DIgSILENT Power Factory software was executed and all the data required for the analysis were measured and examined for all different areas of the system The procedure used for developing the PV curve for the IEEE 39 bus power network system was based on the following:

- The study focused on real power at load points vulnerable to voltage collapse. A constant power factor is assumed for this study.

- The real power of the loads at the network four areas was modeled at different voltage levels. This exercise was done to provide an ideal condition for the PV curve analysis. The idea is based on PV characteristics that when the real power of the loads is scaled up the operating point at the PV curve is anticipated to drop until it reaches a point where the voltage collapse. The effect of increasing the real power of the loads was that 
International Journal of Engineering Research and Technology. ISSN 0974-3154, Volume 13, Number 6 (2020), pp. 1475-1492

(C) International Research Publication House. https://dx.doi.org/10.37624/IJERT/13.6.2020.1475-1492

the voltages dropped.

- The bus voltages at various areas of the system were monitored as the load real power transfer was increased. The monitored bus voltages data are presented at the $y-$ axis and the $\mathrm{x}$-axis represents the real power data of loads on the PV curve.

- The real power of the loads was gradually increased and the bus voltages were monitored until the maximum limit of $0.95 \mathrm{pu}$ is reached. This means that the real power that corresponds to this voltage is at its maximum. Therefore, the load is at its maximum as well.

- The PV curve is based on plotting voltages, against power at the critical busbars

To run the case study the DIgSILENT platform Toolbox "Transmission Network Tools" was used where the PV curve calculation tool was selected.

The procedure used was to scale the loads accordingly so that the system loadability would be calculated. The method is based on finding out the critical point of voltage stability by increasing the power demand until the load flow calculation can no longer converge. In this case under the basic options window in DIgSILENT software an AC load flow, balanced, positive sequence system was considered. Two options for load scaling considered: to scale loads across the whole network or select a set of loads to be scaled. It is also possible to record results for all busbars or just for the selected busbars. In this case, all system loads were scaled together and the results for all busbars were calculated. The algorithm for the PV curve calculation used iteration control for the load flow with an initial load scaling with a multiplication factor of one. It also used an Adaptive Step Size Algorithm in DIgSILENT where the step size was defined as follows:

- Initial step size $1 \%$ of the initial active and reactive power

- Maximum step size $1 \%$ of the initial active and reactive power

- Minimum step size $0.01 \%$ of the initial active and reactive power

- Maximum iterations 100 of the initial active and reactive power

To achieve the maximum real power margin of the whole system for the loads used in the network, the procedure was to simulate the base case and record the results. The simulation was performed by increasing the total real power load in small steps usually $1 \%$ or less of load increase per step and then the case study was executed. Continue with this step until the maximum loading is reached or the nose point is reached. When the system has reached the maximum loading it is said that the system is stressed and therefore it is operating at a critical point of the power margin. The load flow performed 70 times, 69 converged and 1 diverged.

The next procedure was to plot the PV curve of the critical bus. In this case, bus 08 was identified as the critical bus, as shown in Figure 5 below. The PV curve calculated for the IEEE 39 bus system shows that the initial load demand was $6070.8 \mathrm{MW}$ when the bus voltage was at $1.006 \mathrm{pu}$ and the system was still stable.
Gradually the active power of the whole system was increased until the voltage at the bus 08 reaches $0.95 \mathrm{pu}$ and the whole system's active power demand was $7709.918 \mathrm{MW}$. It presents a $28 \%$ increase of the initial active power load demand. At this point, the system was still regarded as stable although it had reached a maximum voltage stability margin. At this point, all the buses in the system were monitored individually and the system was heavily loaded and exposed to voltage collapse. When the system load demand reached 8886.7 MW the voltage at bus 08 dropped to 0.733 pu as shown in the curve in Figure 5 and the whole system was beyond recovery. This means that it was at a zone of voltage collapse.

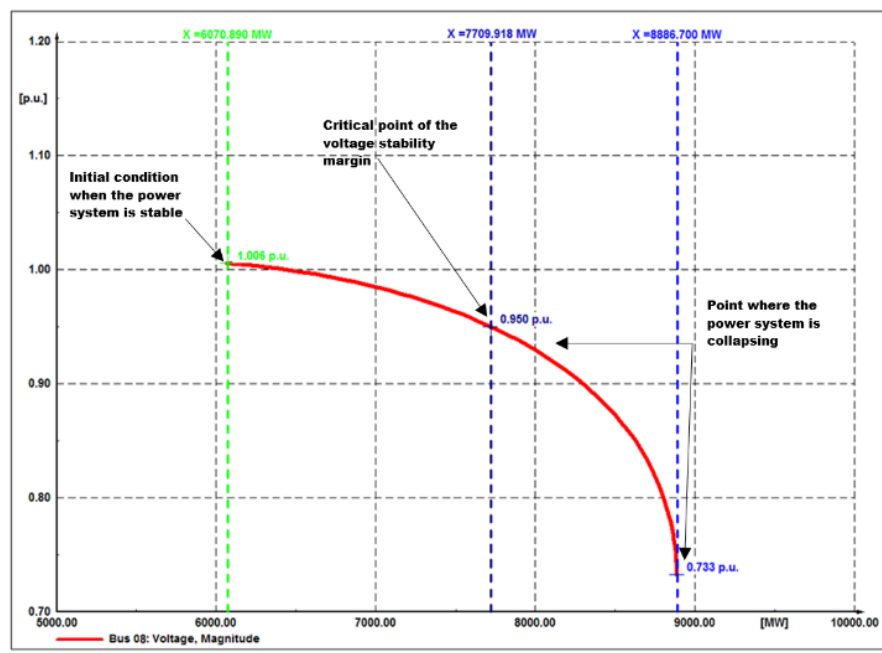

Fig. 5: The PV curve calculation of the whole system

Table 4: The Bus Voltage Magnitude $u$, in pu. when the system load demand is at 7709.918 MW

\begin{tabular}{|c|c|c|c|}
\hline \multirow{14}{*}{ 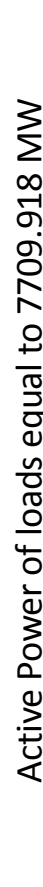 } & \multicolumn{3}{|c|}{ Bus Voltages Magnitude $\mathrm{u}$, in pu. } \\
\hline & $\begin{array}{l}\text { Bus 01 } \\
1.035895616\end{array}$ & $\begin{array}{l}\text { Bus 02 } \\
1.043494247\end{array}$ & $\begin{array}{l}\text { Bus 03 } \\
0.996317581\end{array}$ \\
\hline & $\begin{array}{l}\text { Bus 04 } \\
0.952281804\end{array}$ & $\begin{array}{l}\text { Bus 05 } \\
0.960734764\end{array}$ & $\begin{array}{l}\text { Bus 06 } \\
0.9674696\end{array}$ \\
\hline & $\begin{array}{l}\text { Bus } 07 \\
0.950698175\end{array}$ & $\begin{array}{l}\text { Bus } 08 \\
0.949014873\end{array}$ & $\begin{array}{l}\text { Bus } 09 \\
1.00531447\end{array}$ \\
\hline & $\begin{array}{l}\text { Bus } 11 \\
0.973779197\end{array}$ & $\begin{array}{l}\text { Bus } 12 \\
0.95221973\end{array}$ & $\begin{array}{l}\text { Bus 13 } \\
0.971130211\end{array}$ \\
\hline & $\begin{array}{l}\text { Bus } 14 \\
0.960489876\end{array}$ & $\begin{array}{l}\text { Bus } 15 \\
0.961669386\end{array}$ & $\begin{array}{l}\text { Bus } 16 \\
1.023442676\end{array}$ \\
\hline & $\begin{array}{l}\text { Bus } 17 \\
0.992052157\end{array}$ & $\begin{array}{l}\text { Bus } 18 \\
0.991589802\end{array}$ & $\begin{array}{l}\text { Bus } 19 \\
1.031601027\end{array}$ \\
\hline & $\begin{array}{l}\text { Bus 20 } \\
0.977827156\end{array}$ & $\begin{array}{l}\text { Bus } 21 \\
0.993864074\end{array}$ & $\begin{array}{l}\text { Bus 22 } \\
1.025212775\end{array}$ \\
\hline & $\begin{array}{l}\text { Bus 23 } \\
1.013668414\end{array}$ & $\begin{array}{l}\text { Bus 24 } \\
0.983109306\end{array}$ & $\begin{array}{l}\text { Bus 25 } \\
1.036779144\end{array}$ \\
\hline & $\begin{array}{l}\text { Bus 26 } \\
1.023442676\end{array}$ & $\begin{array}{l}\text { Bus } 27 \\
0.999894221\end{array}$ & $\begin{array}{l}\text { Bus 28 } \\
1.034859663\end{array}$ \\
\hline & $\begin{array}{l}\text { Bus 29 } \\
1.039937252\end{array}$ & $\begin{array}{l}\text { Bus } 30 \\
1.047500067\end{array}$ & $\begin{array}{l}\text { Bus } 31 \\
0.981999993\end{array}$ \\
\hline & $\begin{array}{l}\text { Bus 32 } \\
0.983100006\end{array}$ & $\begin{array}{l}\text { Bus 33 } \\
0.997200081\end{array}$ & $\begin{array}{l}\text { Bus 34 } \\
1.012300093\end{array}$ \\
\hline & $\begin{array}{l}\text { Bus 35 } \\
1.049300022\end{array}$ & $\begin{array}{l}\text { Bus } 36 \\
1.040000028\end{array}$ & $\begin{array}{l}\text { Bus 37 } \\
1.02780002\end{array}$ \\
\hline & $\begin{array}{l}\text { Bus 38 } \\
1.026500065\end{array}$ & $\begin{array}{l}\text { Bus 39 } \\
1.03\end{array}$ & \\
\hline
\end{tabular}

The results in Table 4 show that at load demand of 7709.918 MW to the system, all the 39 buses were still within the limitation although the load demand has reached the maximum power margin. As the IEEE 39 Bus system was divided into Area A, 
International Journal of Engineering Research and Technology. ISSN 0974-3154, Volume 13, Number 6 (2020), pp. 1475-1492

(C) International Research Publication House. https://dx.doi.org/10.37624/IJERT/13.6.2020.1475-1492

Area B, Area C, and Area D, it was possible to identify which area was mostly affected. In this case, Area B is the most affected area since Bus 08 is identified as the closest bus to violate the voltage limit. Although the system is heavily loaded at this point it still has a good chance to return to voltage stability.

\section{III.5. Case study 2}

The case study aimed to analyze the active, reactive and apparent power demands of the individual load in each area when the system is at the critical point

When the total active power of the system was at 7709.918 MW the next task was to calculate using DIgSILENT the power load demands magnitude of the individual loads. Load 03, load 18, and load 25 are situated in Area A and the active powers were calculated as 408.9399815MW for load 03, 200.659993MW for load 18, and 284.4799971 MW for load 25 respectively.

The loads 04, 07, 08, 12, 31, and 39 respectively belong to Area B. Area $\mathrm{C}$ in the system consists of loads 26, 27, 28, and 29 respectively. Area D contains loads 15, 16, 20, 21, 23, and 24. When all the load active power demands were added together for Area A, Area B, Area C, and Area D produced 7709.918 MW as shown in Table 5.

Table 5 The Active, Reactive, and apparent power load demand for the individual loads of the system

\begin{tabular}{|l|l|l|l|}
\hline Name & $\begin{array}{l}\text { Active Power } \\
\text { MW }\end{array}$ & $\begin{array}{l}\text { Reactive } \\
\text { Power Mvar }\end{array}$ & $\begin{array}{l}\text { Apparent } \\
\text { Power MVA }\end{array}$ \\
\hline Load 03 & 408.9399815 & 3.047961451 & 408.9513401 \\
\hline Load 04 & 634.9999837 & 233.6799575 & 676.632324 \\
\hline Load 07 & 296.9259979 & 106.6799885 & 315.5085865 \\
\hline Load 08 & 662.9399861 & 223.5199716 & 699.6074635 \\
\hline Load 12 & 9.525002758 & 111.7599965 & 112.1651572 \\
\hline Load 15 & 492.3817934 & 194.3099395 & 529.3356053 \\
\hline Load 16 & 417.8299794 & 41.02094758 & 419.8387903 \\
\hline Load 18 & 200.659993 & 38.09997624 & 204.2450513 \\
\hline Load 20 & 797.5599736 & 130.8098766 & 808.2160202 \\
\hline Load 21 & 347.9799985 & 146.0499494 & 377.3866281 \\
\hline Load 23 & 314.3249995 & 107.4419543 & 332.1806419 \\
\hline Load 24 & 391.9219976 & 117.0939417 & 409.0401488 \\
\hline Load 25 & 284.4799971 & 59.94396814 & 290.7269304 \\
\hline Load 26 & 176.529993 & 21.5899764 & 177.8453416 \\
\hline Load 27 & 356.8699899 & 95.8849497 & 369.5268776 \\
\hline Load 28 & 261.6199903 & 35.0519609 & 263.9576847 \\
\hline Load 29 & 360.0449846 & 34.16294565 & 361.6621321 \\
\hline Load 31 & 11.6839997 & 5.841999851 & 13.06310879 \\
\hline Load 39 & 1282.70003 & 431.7998824 & 1353.429166 \\
\hline Total & $\mathbf{7 7 0 9 . 9 1 8 6 7 2}$ & $\mathbf{2 1 3 7 . 7 9 0 1 4 4}$ & $\mathbf{8 1 2 3 . 3 1 8 9 9 8}$ \\
\hline
\end{tabular}

The results were analyzed when the system has reached the critical power transfer and the following was discovered. In Area A,bus03, bus 17, and bus 18 the voltage dropped, but it was still within the lower voltage limits. The rest of the bus voltages stayed at $1 \mathrm{pu}$, therefore, Area A was regarded as stable when the load demand of the system was at 7709.918 MW. Analyzing the results based on voltage profile Bus 03 voltage was recorded as $0.996 \mathrm{pu}$, Bus 17 voltage is $0.992 \mathrm{pu}$ and bus 18 is $0.992 \mathrm{pu}$ respectively. It was then concluded that bus 18 voltage is a critical one for Area A. The results also show that none of the other components in Area A experience overloading.

It was also discovered that G Area B Bus 08 was the critical bus concerning voltage stability. The voltage value for Bus 08 was recorded as $0.949 \mathrm{pu}$. Area $\mathrm{C}$ was not affected when the load demand was 7709.918 MW. Area D shows that Bus 15 at 0.962 pu was identified as the critical bus and Generator G05 maximum loading limits were recorded as $80.3 \%$. This means that the system was under stress.

With the above, the analysis of the whole IEEE 39 bus system was completed. The results provided all critical points that needed to be monitored when the system was operating at the maximum power transfer. The maximum power transfer was determined using the PV curve calculation and it was discovered to be $7709.918 \mathrm{MW}$. It was discovered under this condition that Bus 08 was the critical bus for the whole system and its magnitude was recorded as $0.949 \mathrm{pu}$. The next case study determines the influence of the system's active power increase over the system process of collapse. This case study utilized the PV curve analysis.

\section{III.6. Case study 3}

The case study aims to find a point of system collapse beyond the critical point when the power system is collapsing. The system's active power load demand was initially $6070.8 \mathrm{MW}$ and the system was stable. A load flow with an iteration number starting from 1 up to 70 was simulated. It was discovered from the results that for the iteration from 1 up to 28 , the system stayed stable. At iteration 28 the system load demand was calculated as 7709.918MW and the results show that the maximum power transfer was reached. At this condition, the system was operating at a critical point. The results show that the system was still stable because the bus voltages were within the limits. To analyze the performance of the 39 bus system under voltage instability, the iterations were repeated until the system collapsed. The procedure applied was based on increasing the load demand by the increment of $1 \%$ as the iterations were increased. The focus was strictly based on all the iteration after the $28^{\text {th }}$ one and monitoring how the increase of the load demand influenced the whole system behavior.

\section{III.6.1 IEEE 39 Bus system reached a point of collapsing}

When the system demand was increased to 7770.627MW the voltage magnitudes of buses 04,07 , and 08 dropped below the lower voltage limits. Therefore, in the areas where these buses are located the system approached instability. When the load demand was increased to 7831.334822 MW in addition to the Buses 04, 07,08, and Bus 12 were exposed to lower voltage limits conditions. When the load demand was increased to 7892.043 MW Buses 04, 05, 07, 08, 12, and Bus14 were exposed to voltage drop. At a load demand of 8013.458885 MW buses, 06 and 15 were added to the Buses 04, 07, 08,12, and Bus 14. When the load demand was increased to $8134.875 \mathrm{MW}$ the next bus that was added to the previous buses was bus 11. At load demand of 8256.290968 MW, an additional bus 10 had voltage lower than 
International Journal of Engineering Research and Technology. ISSN 0974-3154, Volume 13, Number 6 (2020), pp. 1475-1492

(C) International Research Publication House. https://dx.doi.org/10.37624/IJERT/13.6.2020.1475-1492

the low limit. As the load demand continue to increase to 8499.123 MW, Bus 24 was added. The results show that at a load demand of 8559.831 MW Bus 03 and Bus 18 were simultaneously added to the group of buses with lower than the low limit voltages. At the load demand of 8696.424 MW, Bus 09 was added. At a point where the load demand by the whole system was 8772.309 MW Bus 21 and Bus 27 were simultaneously added to the group of buses with lower than the low limit voltages. Finally, it was observed from the load flow results that initially when the load demand started to increase from the critical point, only three buses were affected. When the point of the system collapse was approached Buses 03, 04, 05, 06, 07, 08, 09, 10, 11, 12, 13, 14, 15, 16, 17, 18, 21, 24 and 27 were affected. The case study was concluded and the sequence of buses that were influenced by increasing the load demand was also determined. The amount of $8696.427 \mathrm{MW}$ represents a $44.5 \%$ increase in the initial power load demand in the whole system.

The PV curve is shown in Figure 5 that there was no control mechanism after the load demand of 7709.918 MW was reached by the system. If continued to supply more power to the loads the bus voltages at the critical buses also continued to drop until it reached a point where the system was not able to recover and the whole system was therefore exposed to voltage collapse. At this point, the total load demand for the system is $8886 \mathrm{MW}$. Therefore the system would not recover from the voltage instability. Table 6 below represents the results that were recorded when the system was at the load demand of 8886.7 MW.

Table 6: The Bus Voltage Magnitude u, in p.u. when the system load demand is at point of voltage collapse (8886.7 MW)

\begin{tabular}{|c|c|c|c|}
\hline \multirow[b]{5}{*}{$\begin{array}{l}\infty \\
\infty \\
\infty\end{array}$} & \multicolumn{3}{|c|}{ Bus Voltages Magnitude $\mathrm{u}$, in pu. } \\
\hline & $\begin{array}{l}\text { Bus } 01 \\
0.988110696\end{array}$ & $\begin{array}{l}\text { Bus } 02 \\
1.025697234\end{array}$ & $\begin{array}{l}\text { Bus } 03 \\
0.880310286\end{array}$ \\
\hline & $\begin{array}{l}\text { Bús } 04 \\
0.744817067\end{array}$ & $\begin{array}{l}\text { Bus 05 } \\
0.746118024\end{array}$ & $\begin{array}{l}\text { Bus } 06 \\
0.761768686\end{array}$ \\
\hline & $\begin{array}{l}\text { Bus } 07 \\
0.732349881\end{array}$ & $\begin{array}{l}\text { Bus 08 } \\
0.731662782\end{array}$ & $\begin{array}{l}\text { Bus 09 } \\
0.899022339 \\
\end{array}$ \\
\hline & $\begin{array}{l}\text { Bus 10 } \\
0.813841624\end{array}$ & $\begin{array}{l}\text { Bus 11 } \\
0.792649188\end{array}$ & $\begin{array}{l}\text { Bus 12 } \\
0.758667322\end{array}$ \\
\hline$\stackrel{0}{ \pm}$ & $\begin{array}{l}\text { Bus 13 } \\
0.792177132\end{array}$ & $\begin{array}{l}\text { Bus 14 } \\
0.76725736\end{array}$ & $\begin{array}{l}\text { Bus 15 } \\
0.822980319\end{array}$ \\
\hline$\frac{\text { O্ }}{\partial}$ & $\begin{array}{l}\text { Bus 16 } \\
0.894384399\end{array}$ & $\begin{array}{l}\text { Bus 17 } \\
0.897658211\end{array}$ & $\begin{array}{l}\text { Bus 18 } \\
0.887327793\end{array}$ \\
\hline ñ & $\begin{array}{l}\text { Bus-19----- } \\
0.996116116\end{array}$ & $\begin{array}{r}\text {-Burs-20----- } \\
0.955598762\end{array}$ & $\begin{array}{l}\text {-Burs-24------ } \\
0926358952\end{array}$ \\
\hline$\frac{0}{4}$ & $\begin{array}{l}\text { Bus } 22 \\
0.988616819\end{array}$ & $\begin{array}{l}\text { Bus 23 } \\
0.975088265\end{array}$ & $\begin{array}{l}\text { Bus 24 } \\
0.89701584\end{array}$ \\
\hline$\sum_{3}^{\frac{1}{3}}$ & $\begin{array}{l}\text { Bus 25 } \\
0.990688397\end{array}$ & $\begin{array}{l}\text { Bus 26 } \\
0.96642025\end{array}$ & $\begin{array}{l}\text { Bus 27 } \\
0.922906052\end{array}$ \\
\hline$\stackrel{0}{0}$ & $\begin{array}{l}\text { Bus 28 } \\
1.011199714\end{array}$ & $\begin{array}{l}\text { Bus } 29 \\
1.016214282\end{array}$ & $\begin{array}{l}\text { Bus } 30 \\
1.047500014\end{array}$ \\
\hline : & $\begin{array}{l}\text { Bus } 31 \\
0.981999993\end{array}$ & $\begin{array}{l}\text { Bus } 32 \\
0.869494\end{array}$ & $\begin{array}{l}\text { Bus } 33 \\
0.997200012\end{array}$ \\
\hline & $\begin{array}{l}\text { Bus 34 } \\
1.0123\end{array}$ & $\begin{array}{l}\text { Bus } 35 \\
1.0493\end{array}$ & $\begin{array}{l}\text { Bus } 36 \\
1.04\end{array}$ \\
\hline & $\begin{array}{l}\text { Bus 37 } \\
1.0278\end{array}$ & $\begin{array}{l}\text { Bus 38 } \\
1.0265\end{array}$ & $\begin{array}{l}\text { Bus } 39 \\
1.03\end{array}$ \\
\hline
\end{tabular}

In Table 6 above the buses shown in bold are below the lower voltage limits meaning that the system was no longer stable. The worst critical bus in the case study was identified as the Bus 08 because it has the highest voltage drop. The location of this bus was discovered to be in Area B. The results also show that the most affected area in the case study was Area B.

\section{III.6.2 Results obtained for Area A}

The load flow results show that the system reached a point where it was no longer stable. In Area A it can be seen that buses 03,17 , and 18 voltages were now below the lower voltage limits. The voltage of bus 03 was recorded as 0.880 pu and for bus 17 as $0.898 \mathrm{pu}$ and for bus 18 as $0.887 \mathrm{pu}$. For the Area, A bus 03 was identified as the critical bus. The rest of the buses in Area A remain stable when the load demand was 8886.7 MW. For the loading limits of the edge elements, the results show that the line 03-04 and the line 02-03 also experienced overloading. The results show that the two lines loaded beyond $100 \%$ where lines 03-04 was loading at $129.4 \%$ and the line 02-03 at $121.9 \%$ respectively. Lastly, the results also showed that generator 08 was $87.6 \%$ loaded and the transformer Trf 25-37 was $85.2 \%$ loaded. The rest of the elements were within the limits and therefore there is no need to attend to them

\section{III.6.3 Results obtained for Area B}

The next location that was monitored was Area B. The results showed that Area B was the area exposed to the worst voltage instability. Area B buses 31, 32, and 39, the voltage dropped from $1 \mathrm{pu}$ to below $0.95 \mathrm{pu}$. It was discovered that the critical bus that represents the whole system was also situated within the Area B. The load flow results also showed that all the maximum loading limits of the edge elements were violated exclude for the generator G1, the transformer Trf 11-12, the transformer Trf 1312 , the line 01-39, and the line 04-14 respectively. The maximum loading results of the edge elements are detailed in Table 7 below.

Table 7: Maximum loading of the edge elements results at Area B

\begin{tabular}{|c|c|}
\hline $\begin{array}{l}\text { Name of the edge } \\
\text { element line }\end{array}$ & $\begin{array}{l}\text { Maximum loading of the } \\
\text { edge element in percentage (\%) }\end{array}$ \\
\hline Line 03-04 & 129.4 \\
\hline Line 04-05 & 149.6 \\
\hline Line 05-06 & 126.2 \\
\hline Line 05-08 & 96.1 \\
\hline Line 06-07 & 112.8 \\
\hline Line 06-11 & 130.6 \\
\hline Line 07-08 & 146.6 \\
\hline Line 08-09 & 133.3 \\
\hline Line 09-39 & 130 \\
\hline Line 10-11 & 127 \\
\hline Line 10-13 & 116 \\
\hline Line 13-14 & 121 \\
\hline Line 14-15 & 136.2 \\
\hline Trf 06-31 & 139 \\
\hline Trf 10-32 & 112 \\
\hline G02 & 137.8 \\
\hline G03 & 110.1 \\
\hline
\end{tabular}

\section{III.6.4 Results obtained for Area $C$}

The next location that was monitored was Area C., In this case, Bus 27 was identified as the critical point where the magnitude of the voltage dropped to $0.923 \mathrm{pu}$. The maximum loading limits of the edge elements showed was G 09 to be $82.3 \%$ loaded. The rest of the components in Area $\mathrm{C}$ were within the limits. 
International Journal of Engineering Research and Technology. ISSN 0974-3154, Volume 13, Number 6 (2020), pp. 1475-1492

(C) International Research Publication House. https://dx.doi.org/10.37624/IJERT/13.6.2020.1475-1492

\section{III.6.5 Results obtained for Area D}

The results in Area D showed that buses 15, 16, 21, and 24 voltages were below the lower voltage limits. These voltages results were recorded as 0.823 pu for bus $15,0.894$ pu for bus 16 , $0.926 \mathrm{pu}$ for bus 21 , and $0.897 \mathrm{pu}$ for bus 24. The maximum loading limits of the edge elements that were violated are as follows: G04 loaded 92.1\%, G05 loaded $89.3 \%$, G06 loaded $96.9 \%$, G07 loaded $83.4 \%$, Trf 23 - 36 loaded $86.0 \%$, Line 1415 loaded 136.6\%, Line 15-16 loaded 149.1\%, and Line 21-22 loaded $80.3 \%$. The rest of the elements are within the limits and therefore there is no need to attend to them.

At this point, the load flow results were completed and analyzed. The next step was to use the RMS/EMT simulation tool for further investigation. The RMS/EMT Simulation was also performed to find out at what point the system collapsed when load demand was increased at an increment of $1 \%$ for every 1 second.

\section{III.7. Case study 4}

The case study aimed to use the RMS/EMT Simulation toolbox to monitor the load buses time behavior and see how they are influenced when the system loads are increased in Areas A, B, C, and $\mathrm{D}$. To monitor the results of the studied areas, it was required to define the bus voltage that was measured. For Area A these were for buses 03, 18 and 25; for Area B the buses are 04, 07, 08, 12, 31 and 39; for Area C: buses 26, 2728 and 29 and Area D: buses $15,16,20,21,23$, and 24 . The voltage magnitude pu variable represented as (m: ul) were selected for all buses stated above in the selection window in DIgSILENT power factory software. The m:ul variable was found under the variable sets for current, voltage, and power windows.

To understand the behavior of the identified buses, the variables were required to be defined for the loads that are connected to the buses. The variables for the loads were the Total Active Power (m:Psum:bus1). The other components that monitored were the Generators. The variables that were defined for the generators were the Active Power (m:P:bus1), Speed (s:xspeed), Generators Terminal Voltage (s:ut), and the Excitation Voltage (s:ve). All the above variables were represented in per unit (p.u). The toolbox RMS/EMT Simulation toolbox was used for voltage stability analysis. The load event case study needed to be defined and the steps needed to be followed are described below:

\section{III.7.1 The calculation of the initial condition}

To perform the case study, an initial condition needed to be calculated. In DIgSILENT power factory software, this normally can be done using two simulation methods. The first method is the RMS value Electromagnetic Transients (EMT) and the second method is the instantaneous value Electromagnetic Transients (EMT). In this case, the RMS value Electromagnetic Transients (EMT) were selected. The second step that needed to be considered when calculating the initial condition was network representation. The calculation method for network presentation has two options, which are as follows: balanced, positive sequence, and unbalanced three-phase (ABC). A balanced, positive sequence was selected for the simulated network. The third step was to select the simulation events. A load event was the type of contingency selected for this case study. The load event case study consists of Execution Time, Event for Single Load / Multiple Loads, Event of the Load, and Proportional Load Step.

\section{III.7.2 The execution time}

When the initial condition is running at some point the load event will need to be introduced to the process. The moment at which the load event is introduced is called execution time. It has three absolutes which are hours (h) minutes (min) and seconds (s). In this case study, the second absolute is considered. The execution time for the simulation was chosen to be 15 seconds.

\section{III.7.3 The type of events for loads}

There are two types of events. The first is a single load application. In this case, the contingency is only applied to one specific load in the system and the investigation is how it affects the behavior of the whole system. The second is when the contingency is applied to multiple loads in the system. In this case study, the second type was used. and simultaneously implemented to all 19 loads.

\section{III.7.4 Load Events}

At a point where the RMS/EMT simulation for the event is considered, the powers of the system loads can be changed in two ways, namely using a Step function method event where the current or initial powers are changed by a given value in percentage of the normal power at the selected time of the event. Ramp function is where the current or initial power is changed by a given value in the percentage of the normal power over the time specified by the ramp duration, which is in seconds. The load ramping starts at the time of the event. In this case, the load event used the Ramp function. The ramp duration time was selected to be 1 second. It means that the active power increased at an increment of $1 \%$ every 1 second until the system collapses.

\section{III.7.5 The Proportional load step}

A proportional load step is a tool that is used for selecting which power (active or reactive) to be increased. In this case, the active power was considered. After the above selections, the power system was ready to implement the RMS/EMT simulation.

\section{III.7.6 The RMS/EMT Simulations}

Once all the above was completed the calculation of the initial condition was executed. The Newton-Rapson algorithm was then activated. In this case, the 4 load flow iterations were calculated successfully and the initial condition was also calculated. The next step was to simulate with an absolute of 120 seconds window. The simulation was then initialized for 15 seconds predisturbance which was recognized as the steady-state normal condition. Thereafter, a load event was applied to all the loads to create a disturbance. The result output window on DIgSILENT power factory software shows that the simulation was successful 
and there were 84 events and zero errors. The simulation results also show that the active power at the loads during the initial stage between $-0.1 \mathrm{~s}$ up to $15 \mathrm{~s}$ was not changed and the system was in a stable condition. At 15 seconds the event of increasing the active power of all 19 loads was simultaneously executed as shown in Figures $6 \mathrm{a}$ and $6 \mathrm{~b}$ below.
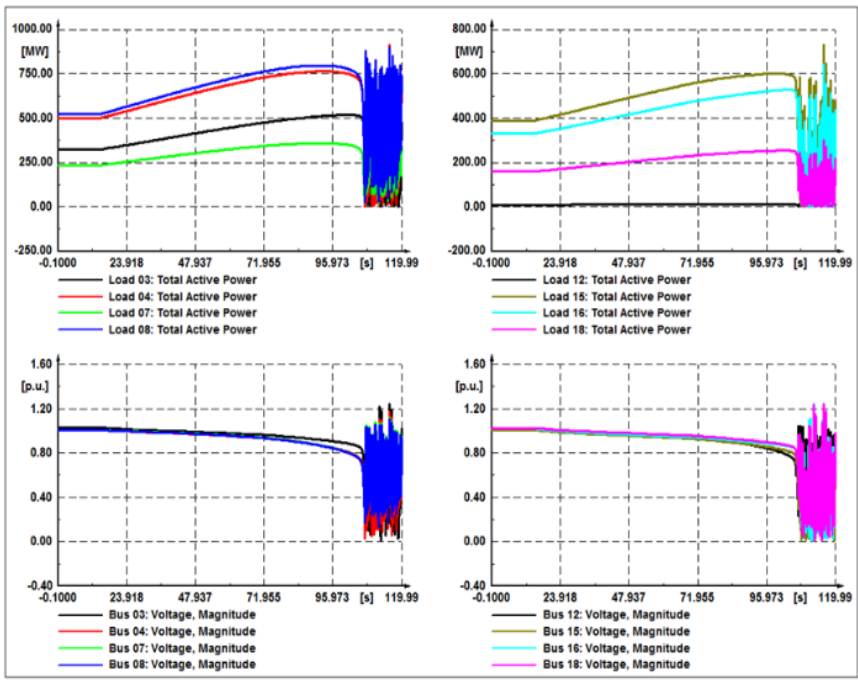

Fig 6a: Time behavior of the active power in MW and voltage magnitudes in p.u for the loads 03 to 18

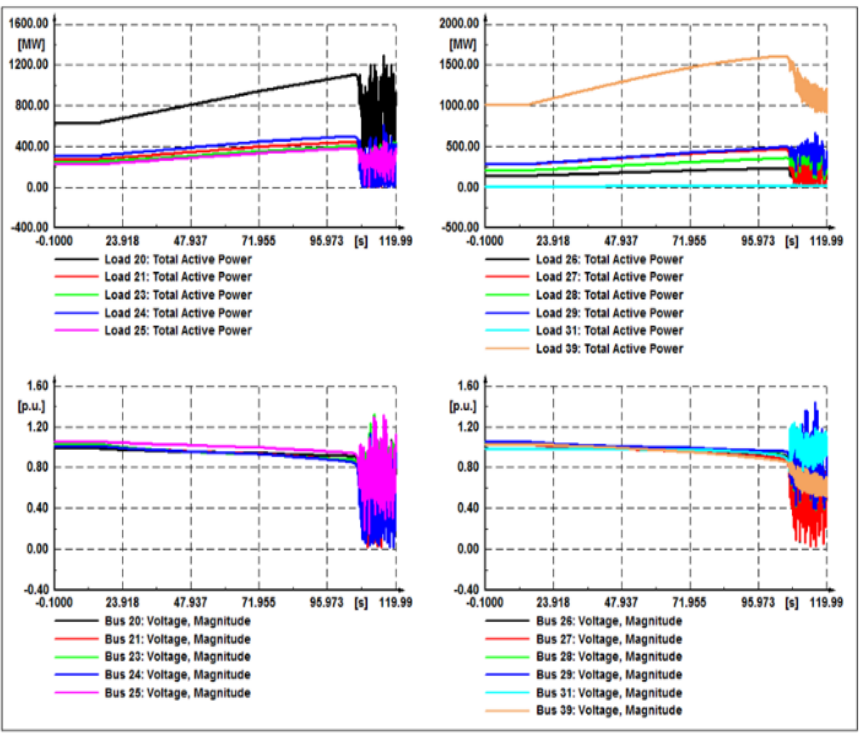

Figure 6b: A Time behavior of the active power in MW and voltage magnitudes in p.u for the loads 20 to 39

The graphs above show that after 15 seconds the active powers of all 19 loads where ramp increased by $1 \%$ every 1 second until the system reached a maximum active power transfer. At this point, a critical bus that was already discovered as Bus 08 earlier in the study, therefore used as a reference case. A more detailed presentation of the time behavior of the Bus 08 is shown in Figure 7 below.

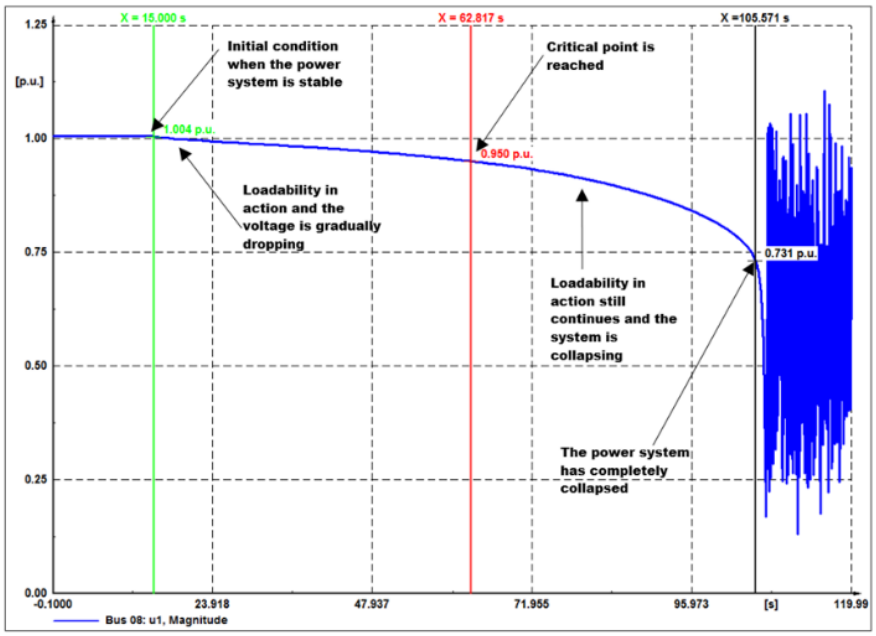

Fig 7: Voltage magnitudes behavior in pu for the critical Bus 08

The PV curve in Figure 7 shown in green represents the initial condition where the load demand was at $522 \mathrm{MW}$ and the voltage magnitude was at $1.004 \mathrm{pu}$. When the load demand was increased to $662.93 \mathrm{MW}$ the magnitude of the voltage dropped to $0.95 \mathrm{pu}$ as shown in red on the graph. At this point, the total loading of the system has reached its critical point for 47.917 seconds. It was discovered that at this point the network under the maximum loadability of $7709.9 \mathrm{MW}$ where it is still stable. In percentage, it was calculated to increase its load by $28 \%$ and still considered to be stable although it has now reached the maximum loadability margin. The load was allowed to continue to increase in this case until a maximum load of 8886.7 MW was reached and the voltage magnitude dropped drastically to 0.731 $\mathrm{pu}$ and shown in black on the graph. The system collapsed for 90.571 seconds. In percentage, it was once again calculated as $46 \%$ of load increase. At this point, the system was collapsing because all the controllers that were used to compensate voltage had reached their limits and therefore the system still required more reactive power support. It was later concluded that any increase of loads from $28 \%$ going up was considered as the worst-case contingency due to the loadability analysis of the system. The RMS/EMT software environment and the obtained dynamic behavior of the load buses active power demand and voltages are used further to investigate the behavior of the system when load shedding schemes are implemented.

\section{III.8. Case study 5}

The aim of this case study to implement in DIgSILENT environment an Undervoltage load shedding scheme to stabilize the system when it is overloaded. Earlier in this paper, a detailed analysis of voltage stability was done and the main objective was to find out which part of the IEEE 39 bus network is most vulnerable under the voltage instability conditions. In the considered case study the implementation of the under-voltage load shedding scheme is analyzed. When power system networks are exposed to various contingencies such as overload or loss of generators and so on, well-co-ordinated protection schemes are used to monitor and control the system. When the protection schemes are applied and the system continues to be unstable a load shedding scheme is deployed as the last resort to stabilize the system using shedding the loads that are causing the system to be unstable. 
The load shedding scheme used in this paper is based on the protective devices wherein a case the voltage elements are used for voltage monitoring. In these cases, the IEEE 39 bus system was considered as a network where a load shedding scheme was required to stabilize the system. The flow chart that was used for these exercises is shown in Figure 8 below

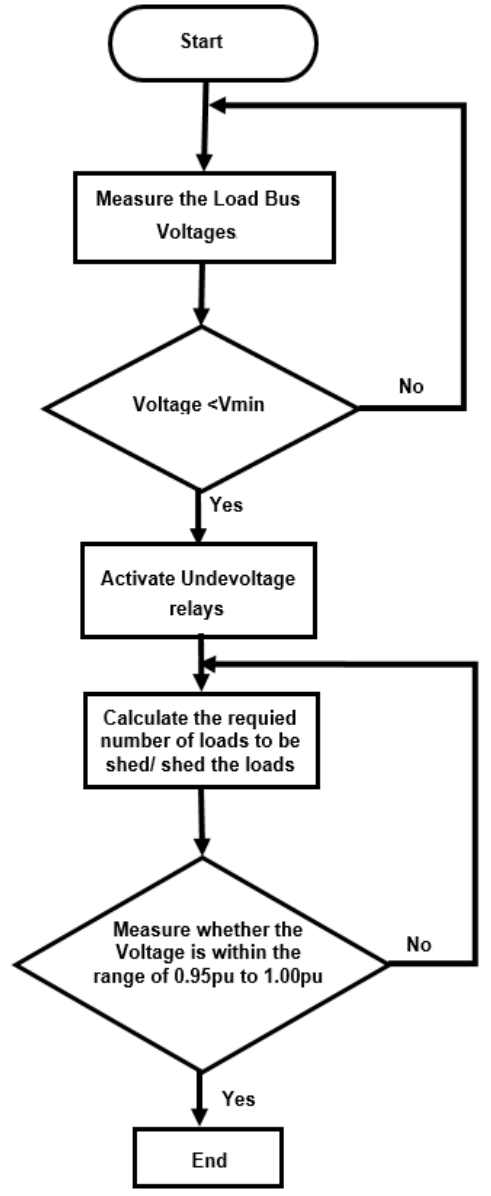

Fig. 8: The flowchart of the Under-Voltage load-shedding scheme

\section{III.8.1 The Under Voltage Load Shedding Schemes implementation in DIgSILENT environments}

Voltage instability in the power systems is caused by two types of contingencies namely generator unit outage and load increase. The common factor for the two contingencies is active and reactive power. When the two contingencies occur the active and reactive power demand increases up to a point where the voltage drop starts. It will, therefore, create an unbalance between the power supply and the load demand. If not attended it will lead to an outage of a heavily loaded transmission line or the large generating unit, therefore, the system may lead toward collapse. Under such conditions, load shedding schemes are generally initiated. This is done when exhausting all other active and reactive controllers and comparators in an attempt to recover the system from the voltage collapse condition.

The load shedding scheme deploys DIgSILENT power factory software as the platform for simulation. The approach is to improve the load bus voltages of the power system under the feasible solution of load flows using an Undervoltage load shedding scheme. Simulations were done, and the load was increased until the system shows that it is overload. Then the Undervoltage relays installed in the system will trip and shed the required loads. However, the under-voltage load shedding relays only trip the load when the load bus voltage is below a given threshold, in this case, is $0.95 \mathrm{pu}$. The initial simulation was executed in the steady-state condition within the acceptable voltage range of $0.95 \mathrm{pu}$ to $1.05 \mathrm{pu}$ in all loaded buses of the system.

In cases such as this experiment a load shedding scheme is required to be implemented as the last resort. The under-voltage load shedding schemes use of static relays called Intelligent Electronic Devices (IEDs). The relays were installed in all load buses in the system and then configured to protect the system from instability when it is overloaded. To avoid repetition Area $\mathrm{B}$ at bus 8 is selected for demonstration of how the relay was installed. The procedure for installing the Undervoltage and relays in the DIgSILENT power factory software was performed as follows:

- Add a relay DIgSILENT model on the load buses

- Define the relay type in this case Undervoltage relay type is selected

- The application selection is considered as the main protection

- Under relay category window in DIgSILENT voltage was selected

- Had to create VT called load 08 VT and its primary Tap is $345000 \mathrm{~L}-\mathrm{L}$, Secondary Tap 100 L-L Both side connection left as YN

- On the DIgSILENT content configuration name IEC Symbol: U<, ANSI Symbol: 27 Function: Undervoltage; Measure type: Voltage (3ph) where the pickup voltage is set as $0.94 \mathrm{pu}$

- In the DIgSILENT Cubicle, a Circuit breaker called Load 08 CB is assigned to the output logic of the relay

\section{III.8.2 Installation and Determination of the Intelligent Electronic Devices (IEDs)}

Once the above was completed the next task was to determine the voltage relay settings and to verify the level of minimum voltage reached before a contingency situation occurs. Under the load cubicle in DIgSILENT relays were installed

The SEL 751A, a Schweitzer Engineering Laboratories Feeder Protection Relay provides an excellent combination of protection, monitoring, control, and communication in an industrial package This relay was selected as the best device to be used for this case study. In the DIgSILENT power factory library, the SEL 751A IEDs model was not available. Therefore, the first step was to import the protective device in the DIgSILENT library. Once the above was completed The SEL 751A IEDs had to be installed into the network, the procedure was as follows:

Step 1: To import the protective device model from the local data where it was saved. In this case, an SEL 751A IED model was selected and imported into the DIgSILENT library.

Step 2: Activate the power system under study which in this case is the 39 Bus system. Step 3: Set up the protective device in all 
International Journal of Engineering Research and Technology. ISSN 0974-3154, Volume 13, Number 6 (2020), pp. 1475-1492

(C) International Research Publication House. https://dx.doi.org/10.37624/IJERT/13.6.2020.1475-1492

the load bus cubicles.

Step 4: Right-click on the circuit breaker which in DIgSILENT is represented as a black box. A window pops up and the new device is selected and the relay model is selected. Once this is done a window called Relay Model-Grid\Bus $03 \backslash$ Cub-1\Relay is developed.

Step 5: Complete the name, type of the relay, its application, and location. Under the relay type, click the drop-down arrow and a drop-down window appears and the project type option is selected. This option roots to the DIgSILENT library where all databases are situated. In the databases under the heading "relays library", various vendors of relays are found. In this case, the SEL vendor is selected, all the relays from SEL appear and the SEL751A is selected

Step 6: Set up the Phase VT because under the Net Elements in DIgSILENT there was no VT. The tab named "create VT" is clicked and a window appeared with all options that needed to be completed to create the VT. A name VT16 was given to make it easy to identify since 19 of the VTs were required. Once again under type, the drop-down arrow was clicked and a new view window with different options appeared and new a project type was selected. A voltage transformer type window appeared that consists of the various model types. The Ideal Voltage transformer model is selected under the primary Taps $354000 \mathrm{~V}$ is completed.

Step 7 Configure the voltage transformer set up. With step 7 the installation of IEDs in the IEEE39 Bus system is completed on all load buses. The next step was to configure the relay.

\section{III.8.3 The Maximum load to be disconnected}

The maximum load to be disconnected is defined by the total loss of generation supply to the network system. In this case, the unbalance between generation and load will be equal to the maximum import and should be compensated by disconnection of a similar amount of load from the network system. In an instance where it is possible to determine the maximum overload of the system, the amount of load that needs to be shed is assumed considering that it is best to shed more rather than too little. In this case, loads are shed in steps to minimize the possibility of shedding too much load in an instance where the overload condition was less severe.

\section{III.8.4 UVLS simulation}

The system was populated with under-voltage IEDs in all loaded buses. They were coordinated in such a way that the relay sheds the loads first at places where the bus voltages are at the lowest values. After shedding the loads, the IED calculates the system parameters to find out if the system is still within the maximum loadability margin. This process is repeated until the system recovers back to stability. Two scenarios were applied to this case study. Scenario one was based on the system when it was overloaded by $28 \%$ and scenario two was based on the worse case when the system was overloaded by $46 \%$.

\section{III.8.4.1 Part one of the system simulation without UVLS scheme and $28 \%$ overloading}

Based on the results from the previous simulations the system was able to be loaded from the initial loading of $6070.8 \mathrm{MW}$ up to $7709.9 \mathrm{MW}$ with no issues of instability but operating at its critical point. At this point, the system loadability was at $28 \%$ and there was no need to apply the under-voltage load shedding scheme. The voltage behaviors in Figure 9a and Figure 9b below show that when the $28 \%$ loadability was applied after 15 seconds the voltage dropped immediately. However, it can be seen that the automatic voltage governors of the system were able to regulate the system voltage and compensate for the loading of the system.

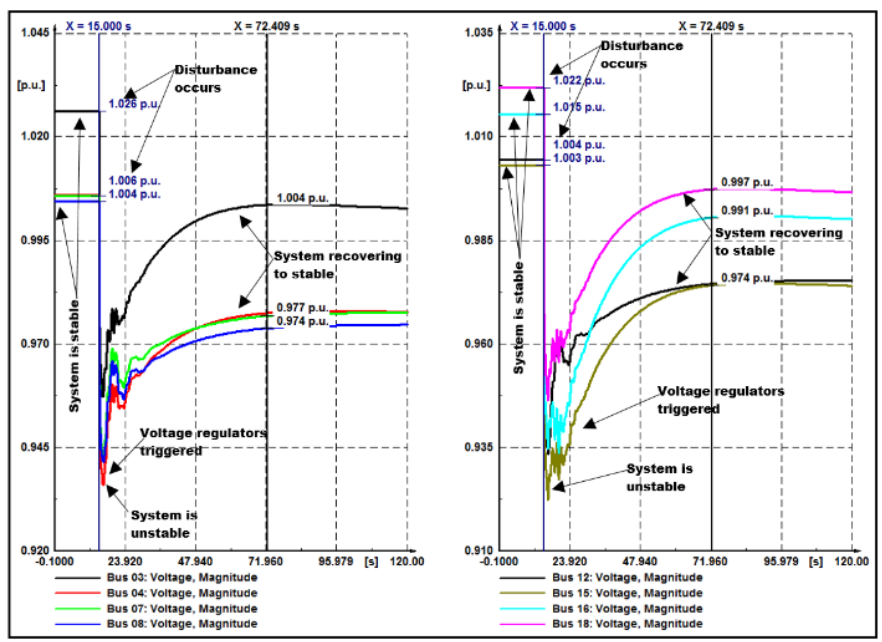

Fig. 9a: The load bus voltage dynamic behavior for the buses 03 to 18 when the system is $28 \%$ overloaded and voltage regulators acted.
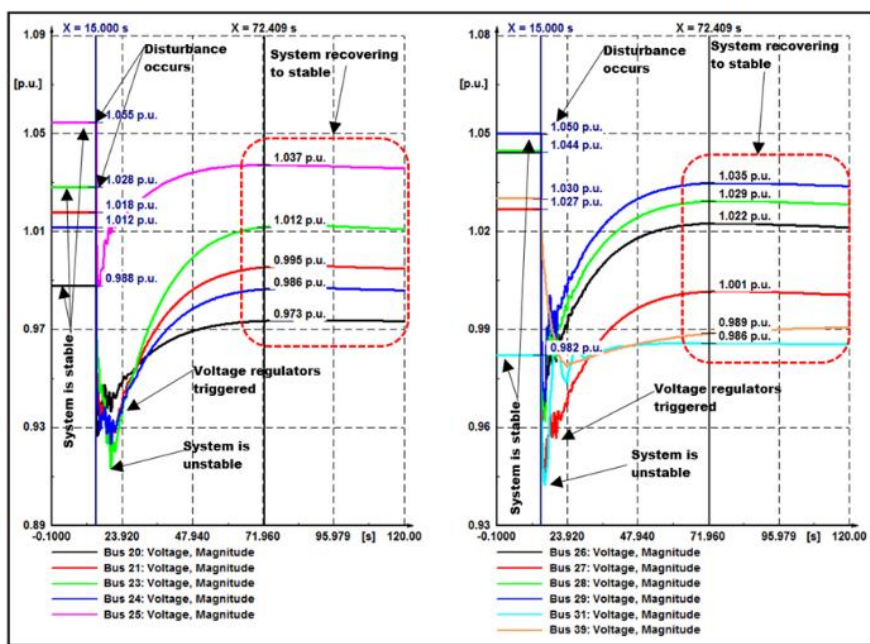

Fig. 9b: The load bus dynamic behavior for the buses 20 to 39 when the system is $28 \%$ overloaded and voltage regulators acted.

At this part of the simulation, based on the $28 \%$ overloading contingency it can be seen that there was no need to introduce the Undervoltage load shedding. The regulators for this scenario where able to recover the system voltage back to a reasonable value which is above $0.95 \mathrm{pu}$ as it can be seen from Table $8(\mathrm{a}, \mathrm{b})$ 
Table 8a: A summary of load bus voltage behavior for the buses 03 to 18 when the system is $28 \%$ overloaded and voltage regulators acted.

\begin{tabular}{|l|l|l|l|}
\hline $\begin{array}{l}\text { Buses } \\
\text { names }\end{array}$ & $\begin{array}{l}\text { Bus values } \\
\text { during the } \\
\text { initial } \\
\text { condition } \\
\text { in p.u }\end{array}$ & $\begin{array}{l}\text { Recovered } \\
\text { bus voltage } \\
\text { values after } \\
\text { disturbance } \\
\text { in p.u }\end{array}$ & $\begin{array}{l}\text { Time is } \\
\text { taken to } \\
\text { recover } \\
\text { in } \\
\text { seconds }\end{array}$ \\
\hline Bus 03 & 1.026 & 1.004 & 57.0409 \\
\hline Bus 04 & 1.005 & 0.977 & 57.0409 \\
\hline Bus 07 & 1.006 & 0.976 & 57.0409 \\
\hline Bus 08 & 1.004 & 0.974 & 57.0409 \\
\hline Bus 12 & 1.004 & 0.974 & 57.0409 \\
\hline Bus 15 & 1.003 & 0.974 & 57.0409 \\
\hline Bus 16 & 1.015 & 0.991 & 57.0409 \\
\hline Bus 18 & 1.022 & 0.997 & 57.0409 \\
\hline
\end{tabular}

Table 8b: A summary load bus behavior for the buses 20 to 39 when the system is $28 \%$ overloaded and voltage regulators

\begin{tabular}{|l|l|l|l|}
\hline $\begin{array}{l}\text { Buses } \\
\text { names }\end{array}$ & $\begin{array}{l}\text { Bus values } \\
\text { during the } \\
\text { initial } \\
\text { condition in } \\
\text { p.u }\end{array}$ & $\begin{array}{l}\text { Recovered bus } \\
\text { voltage values } \\
\text { after } \\
\text { disturbance in } \\
\text { p.u }\end{array}$ & $\begin{array}{l}\text { Time is } \\
\text { taken to } \\
\text { recover in } \\
\text { seconds }\end{array}$ \\
\hline Bus 20 & 0.988 & 0.973 & 57.0409 \\
\hline Bus 21 & 1.018 & 0.995 & 57.0409 \\
\hline Bus 23 & 1.028 & 1.012 & 57.0409 \\
\hline Bus 24 & 1.011 & 0.986 & 57.0409 \\
\hline Bus 25 & 1.044 & 1.037 & 57.0409 \\
\hline Bus 26 & 1.044 & 1.022 & 57.0409 \\
\hline Bus 27 & 1.027 & 1.001 & 57.0409 \\
\hline Bus 28 & 1.044 & 1.029 & 57.0409 \\
\hline Bus 29 & 1.049 & 1.035 & 57.0409 \\
\hline Bus 31 & 0.982 & 0.986 & 57.0409 \\
\hline Bus 39 & 1.029 & 0.989 & 57.0409 \\
\hline
\end{tabular}

III.8.4.2 Part two of the system simulation without UVLS scheme and $46 \%$ loading

The load event in the amount of an overload of $46 \%$ was applied. The results for the affected buses are shown in Figure $10(a, b)$. It can be seen that buses $08,07,04,12$, and 15, went below the minimum lower voltage limit of 0.95 pu. Bus 08 was recorded as the critical bus of the system because it has the highest voltage drop. This was a good indication when the loads that need to be shed have to be prioritized to stabilize the system.
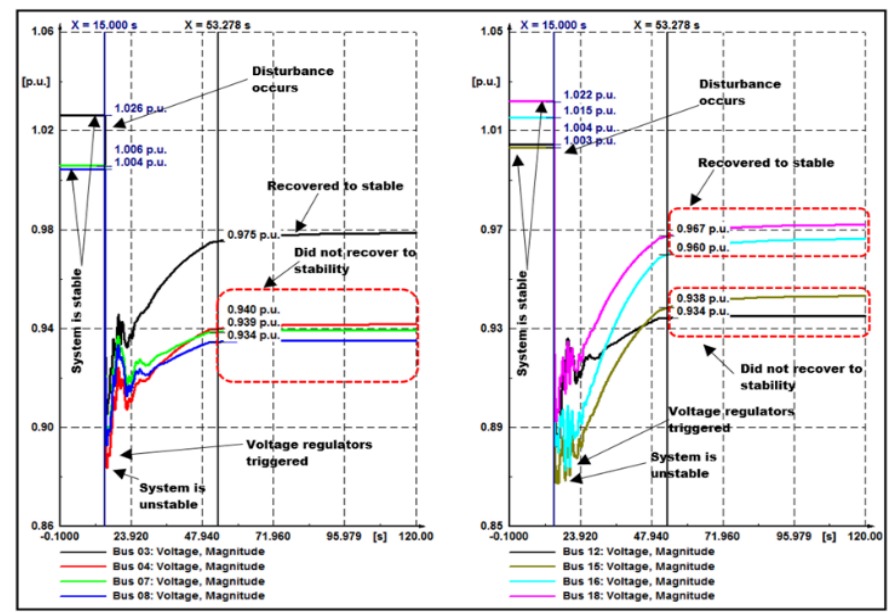

Fig.10a: The load bus voltage dynamic behavior for the Buses 03 to 18 when the system is $46 \%$ overloaded and voltage regulators acted.
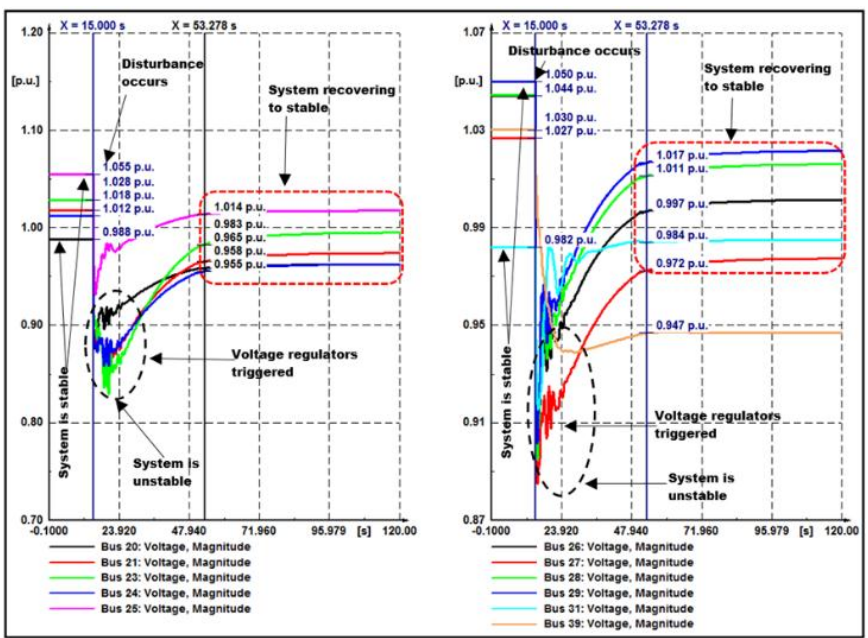

Fig. 10b: The load bus voltage dynamic behavior for Buses 20 to Bus 39 when the system is $46 \%$ overloaded voltage regulators acted.

Immediately after the 15 th second, the power system network was no longer stable and all the voltage regulators became active but could not bring the system to stability for the period 15 th to 20th second. The summary of the results is shown in Tables 9 (a, b) below.

Table 9a: A summary of loaded bus voltage behavior for the Buses 03 to 18 when the system is $46 \%$ overloaded voltage regulators acted.

\begin{tabular}{|l|l|l|l|}
\hline $\begin{array}{l}\text { Buses } \\
\text { names }\end{array}$ & $\begin{array}{l}\text { Bus values } \\
\text { during the } \\
\text { initial } \\
\text { condition } \\
\text { in p.u }\end{array}$ & $\begin{array}{l}\text { Recovered } \\
\text { bus voltage } \\
\text { values after a } \\
\text { disturbance } \\
\text { in p.u }\end{array}$ & $\begin{array}{l}\text { Time is taken } \\
\text { to recover in } \\
\text { seconds }\end{array}$ \\
\hline Bus 03 & 1.026 & 0.975 & 38.278 \\
\hline Bus 04 & 1.005 & 0.940 & 38.278 \\
\hline Bus 07 & 1.006 & 0.939 & 38.278 \\
\hline Bus 08 & 1.004 & 0.934 & 38.278 \\
\hline Bus 12 & 1.004 & 0.934 & 38.278 \\
\hline Bus 15 & 1.003 & 0.938 & 38.278 \\
\hline Bus 16 & 1.015 & 0.960 & 38.278 \\
\hline Bus 18 & 1.022 & 0.967 & 38.278 \\
\hline
\end{tabular}

Table 9b: A summary of loaded bus voltage behavior for the Buses 20 to 39 when the system is $46 \%$ overloaded voltage regulators acted.

\begin{tabular}{|l|l|l|l|}
\hline $\begin{array}{l}\text { Buses } \\
\text { names }\end{array}$ & $\begin{array}{l}\text { Bus values } \\
\text { during the } \\
\text { initial } \\
\text { condition in } \\
\text { p.u }\end{array}$ & $\begin{array}{l}\text { Recovered bus } \\
\text { voltage values } \\
\text { after a } \\
\text { disturbance in } \\
\text { p.u }\end{array}$ & $\begin{array}{l}\text { Time is } \\
\text { taken to } \\
\text { recover in } \\
\text { seconds }\end{array}$ \\
\hline Bus 20 & 0.988 & 0.958 & 38.278 \\
\hline Bus 21 & 1.018 & 1.020 & 38.278 \\
\hline Bus 23 & 1.028 & 1.032 & 38.278 \\
\hline Bus 24 & 1.011 & 1.014 & 38.278 \\
\hline Bus 25 & 1.044 & 1.050 & 38.278 \\
\hline Bus 26 & 1.044 & 1.045 & 38.278 \\
\hline Bus 27 & 1.027 & 1.028 & 38.278 \\
\hline Bus 28 & 1.044 & 1.045 & 38.278 \\
\hline Bus 29 & 1.049 & 1.050 & 38.278 \\
\hline Bus 31 & 0.982 & 0.982 & 38.278 \\
\hline Bus 39 & 1.029 & 1.028 & 38.278 \\
\hline
\end{tabular}


International Journal of Engineering Research and Technology. ISSN 0974-3154, Volume 13, Number 6 (2020), pp. 1475-1492

(C) International Research Publication House. https://dx.doi.org/10.37624/IJERT/13.6.2020.1475-1492

The load Bus 08 was discovered as the worst case as shown in Figure 11. Clearly can be seen that the stability of the system cannot be achieved only with the voltage regulators. The results show that Undervoltage load shedding was required.

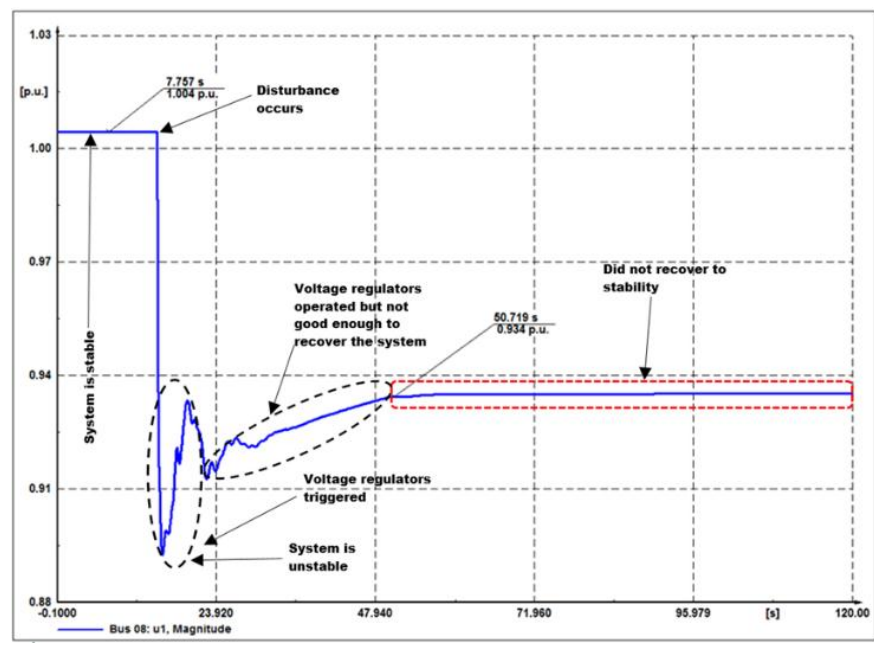

Fig. 11: The results of Bus 8 when the system was overloaded by $46 \%$

III.8.4.3 Part three of the system simulation with UVLS scheme and $46 \%$ loading

The method that is implemented in this case study is based on shedding first the loads where the bus voltage drop is lowest. The scheme is designed in such a manner that it deploys an algorithm proposed in the paper that sheds the loads in 3 stages as shown in Figure 12. Each stage has different priorities to determine the number of loads that need to be shed. The load shedding scheme is fully decentralized according to the load buses. Every load bus has it is under voltage IED. The relays are coordinated in a way that they shed $13 \%$ for stage $1,13 \%$ for stage 2 , and $20 \%$ for stage 3 .

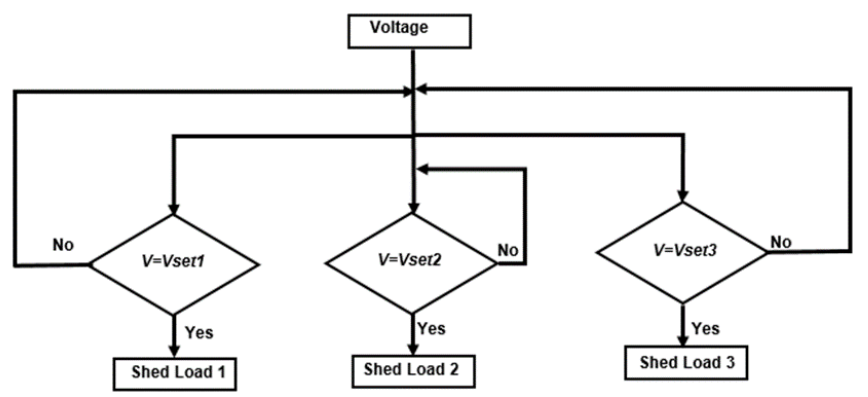

Fig. 12 The algorithm block diagram proposed to shed the loads in 3 stages for every load bus

Figure 12 below shows the results where the UVLS was implemented for Bus 8. When all 3 stages where implemented it can be seen that the voltage at Bus 08 recovered. The results show that it took 20 seconds for the Bus 8 voltage to recover and reach stability.

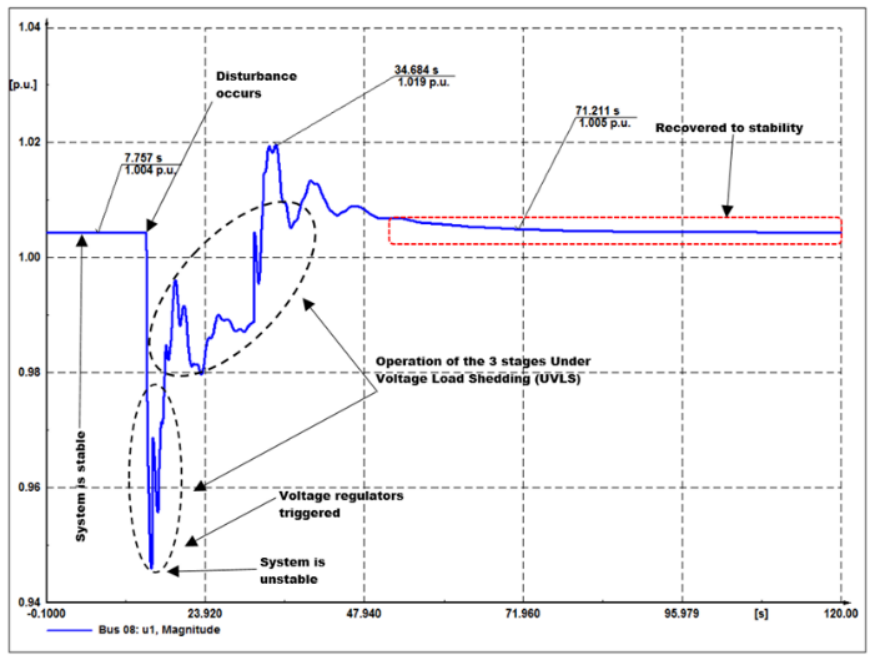

Fig. 12: The system voltage behaviour under overload by $46 \%$ and the UVLS scheme implementation

Figure $13(a, b)$ below represents the behaviour of all load bus voltages in the system. It can now be concluded that by implementing the UVLS scheme the system recovered its stability. The summary of the results is shown in Tables $10(a, b)$ below.

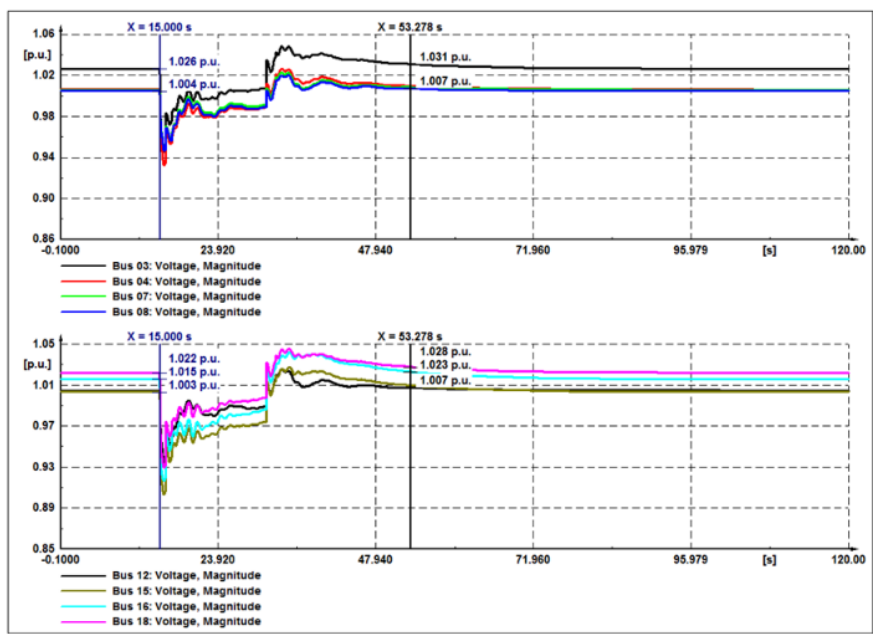

Fig.13a Voltage behavior for buses 03 to 18 under overload by $46 \%$ and the UVLS scheme implementation

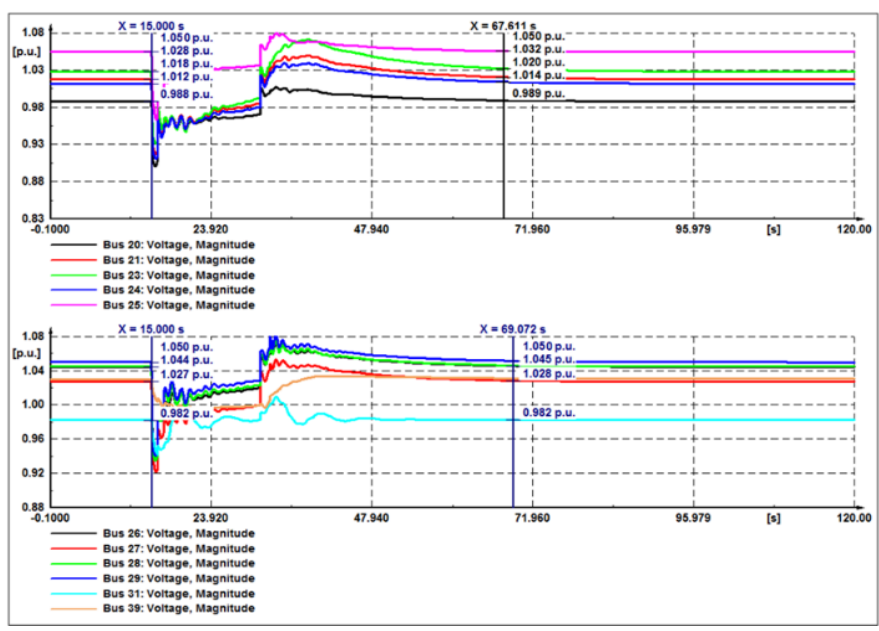

Fig. 13b: Voltage behavior for buses 20 to 39 under overloaded by $46 \%$ and the UVLS scheme implementation 
International Journal of Engineering Research and Technology. ISSN 0974-3154, Volume 13, Number 6 (2020), pp. 1475-1492

(C) International Research Publication House. https://dx.doi.org/10.37624/IJERT/13.6.2020.1475-1492

Table 10a: A summary of voltage behavior for buses 03 to 18 under overloaded by $46 \%$ and the UVLS scheme

$$
\text { implementation }
$$

\begin{tabular}{|l|l|l|l|}
\hline $\begin{array}{l}\text { Buses } \\
\text { names }\end{array}$ & $\begin{array}{l}\text { Bus values } \\
\text { during the } \\
\text { initial } \\
\text { condition in } \\
\text { p.u }\end{array}$ & $\begin{array}{l}\text { Recovered bus } \\
\text { voltage values } \\
\text { after } \\
\text { disturbance in } \\
\text { p.u }\end{array}$ & $\begin{array}{l}\text { Time is } \\
\text { taken to } \\
\text { recover in } \\
\text { seconds }\end{array}$ \\
\hline Bus 03 & 1.026 & 1.031 & 38.278 \\
\hline Bus 04 & 1.005 & 1.007 & 38.278 \\
\hline Bus 07 & 1.006 & 1.007 & 38.278 \\
\hline Bus 08 & 1.004 & 1.007 & 38.278 \\
\hline Bus 12 & 1.004 & 1.007 & 38.278 \\
\hline Bus 15 & 1.003 & 1.007 & 38.278 \\
\hline Bus 16 & 1.015 & 1.023 & 38.278 \\
\hline Bus 18 & 1.022 & 1.028 & 38.278 \\
\hline
\end{tabular}

Table 10b: A summary of voltage behavior for buses 20 to 31 under overload by $46 \%$ and the UVLS scheme implementation

\begin{tabular}{|l|l|l|l|}
\hline $\begin{array}{l}\text { Buses } \\
\text { names }\end{array}$ & $\begin{array}{l}\text { Bus values } \\
\text { during the } \\
\text { initial } \\
\text { condition in } \\
\text { p.u }\end{array}$ & $\begin{array}{l}\text { Recovered bus } \\
\text { voltage values } \\
\text { after } \\
\text { disturbance in } \\
\text { p.u }\end{array}$ & $\begin{array}{l}\text { Time is } \\
\text { taken to } \\
\text { recover in } \\
\text { seconds }\end{array}$ \\
\hline Bus 20 & 0.988 & 0.989 & 38.278 \\
\hline Bus 21 & 1.018 & 1.020 & 38.278 \\
\hline Bus 23 & 1.028 & 1.032 & 38.278 \\
\hline Bus 24 & 1.011 & 1.014 & 38.278 \\
\hline Bus 25 & 1.044 & 1.050 & 38.278 \\
\hline Bus 26 & 1.044 & 1.045 & 38.278 \\
\hline Bus 27 & 1.027 & 1.028 & 38.278 \\
\hline Bus 28 & 1.044 & 1.045 & 38.278 \\
\hline Bus 29 & 1.049 & 1.050 & 38.278 \\
\hline Bus 31 & 0.982 & 0.982 & 38.278 \\
\hline Bus 39 & 1.029 & 1.028 & \\
\hline
\end{tabular}

\section{DISCUSSION}

When the load contingency was implemented the system becomes vulnerable and was exposed to voltage instability. The proposed under-voltage load shedding scheme was then implemented. During this process, the whole power system network was monitored. It was found that the load voltages manage to rise and recover to their initial condition. It is also noted that decentralized loads were shed simultaneously. A three stages topology was used to avoid the condition of over shedding the loads that would lead the system into overvoltage problems. The voltage gradually increased and did not reach 1.05 pu as load shedding was implemented. The results show that the load bus voltages at all multi areas were able to stabilize once all three stages were implemented

The UVLS logic of the soft IEDs was developed and operated successfully in the framework of DIgSILENT power factory software. The soft IEDs were configured to be capable to do load shedding in stages. The developments in this paper extended the capability of the DIgSILENT power factory software to be used for more advanced power stabilities studies. These experiments show that the developed load shedding scheme adjusts well to the magnitude of the disturbances.

The existing software environment of DIgSILENT most papers only focuses to operate in one stage of the load shedding. This case can be dangerous because it leads to under or over shedding which may lead to other problems such as over-voltage in power systems. Therefore, the developed soft IEDs for multi-stage UVLS schemes brought a safer, reliable, and flexible solution

\section{CONCLUSION}

This paper focused on the development of a multi-stage UnderVoltage Load Shedding (UVLS) scheme It is based on the newly developed multi-stage UVLS logic developed in DIgSILENT power factory software environment. The scheme was implemented as a protection mechanism and implemented as the under-voltage elements in the DIgSILENT soft IEDs. This case study made use of loadability events to test the proposed scheme. The IEEE 39 bus system was considered as a case study and modeled in the DIgSILENT power factory software. The power network was decomposed into four areas. The load flow was then implemented and the results were analyzed. The reason for using the load flow was to establish the initial condition of the power network.

The developed multistage UVLS scheme based on DIgSILENT soft IEDs was applied against severe contingencies. When the whole power network system was monitored it was also discovered that the load voltages managed to rise and recover to its initial condition. The results show that during the implementation of the load shedding the load voltages gradually increased and did not reach 1.05 pu. This was a good sign meaning the load bus voltage were able to stabilize after a few seconds and no over-voltage condition occurred in this power system network

When the voltage instability occurred the UVLS scheme automatically started implementing the proposed 3 multi-stages of load shedding. The results obtained provided a better understanding and allowed deep analysis of the UVLS scheme using DIgSILENT power factory environment. Based on the results obtained it can be concluded that the proposed and developed multistage Under-Voltage Load Shedding Scheme using the soft IEDs worked successfully.

\section{ACKNOWLEDGEMENTS}

This work was supported by the TRIP/NRF project, Centre for Substation Automation and Energy Management System (CSAEMS) development and growth, Reference No TP211061100004

\section{REFERENCES}

[1] Kundur, P., 1994. Power system stability and control N. J. Balu \& M. G. Lauby, eds., McGraw Hill, Inc, New York San Francisco.

[2] Taylor, C., 1994. Power system Voltage Stability, McGraw Hill, Inc, New York.

[3] Davidson, D.R., Ewart, D.N. \& Kirchmayer, L.K., 1975. Long term dynamic response of power systems: An analysis of major disturbances. IEEE Transactions on Power Apparatus and Systems, 94(3), pp.819-826.

[4] V. Converti; D.P. Gelopulos; M. Housley; G. Steinbrenner, Long-term stability solution of interconnected power systems, Electrical and Electronics 
Engineers (IEEE) Transactions on Power Apparatus and Systems, vol.95, n.1, January. 1976, pp. 96-104

[5] Inoue, T; Ichikawa T ; P. Kundur P ;Hirsch P., 1995. Nuclear plant models for medium- to long-term power system stability studies. IEEE Transactions on Power Systems, 10(1), pp.141-148.

[6] Martins, N., 1986. Efficient Eigenvalue and Frequency Response Methods Applied to Power System SmallSignal Stability Studies. IEEE Transactions on Power Systems, 1(1), pp.217-224.

[7] Kundur, P Rogers G.J ; Wong D.Y ; Wang L; and Lauby M.G 1990. A comprehensive computer program package for small signal stability analysis of power systems. IEEE Transactions on Power Systems, 5(4), pp.1076-1083.

[8] Mbangula, K.N.I., Davidson, I.E. and Tiako, R., 2016. Improving Power System Stability of South Africa's HVAC Network Using Strategic Placement of HVDC Links. CIGRE Science \& Engineering Journal (CSE), 5, pp.71-78.

[9] Faranda, R., Pievatolo, A. \& Tironi, E., 2007. Load Shedding: A New Proposal. Power Systems, IEEE Transactions on, 22(4), pp.2086-2093.

[10] Nizam, M., Mohamed, A. \& Hussain, A., 2007. An Adaptive Undervoltage Load Shedding Against Voltage Collapse Based Power Transfer Stability Index. Journal of Electrical Engineering \& Technology, 2, pp.420-427.

[11] Chin, V. et al., 2008. Adaptive and optimal under frequency load shedding. In Power Engineering Conference, 2008. AUPEC '08. Australasian Universities. pp. 1-6.

[12] Zahidi, R.A. et al., 2009. Study of Static Voltage Stability Index as an Indicator for Under-Voltage Load Shedding Schemes. Proceedings of ICEE 2009 3rd International Conference on Energy and Environment, pp.256-261.

[13] Yusof, N.A. et al., 2014. Under-voltage load shedding scheme based on voltage stability index for the distribution network. In Clean Energy and Technology (CEAT) 2014, 3rd IET International Conference on. pp. $1-5$.

[14] Pai, M.A. 1989. Energy Function Analysis for Power System Stability, Boston: Kluwer Academic Publishers, pp. 223-227.

[15] T. Shekari, A. Gholami, F. Aminifar, M. Sanaye-Pasand, An Adaptive Wide-Area Load Shedding Scheme Incorporating Power System Real-Time Limitations, Electrical and Electronics Engineers (IEEE), Systems Journal, vol.12, n.1, March 2018, pp.759-767

[16] Sharma V. Kolluri, Fellow IEEE, Jayanth R. Ramamurthy, Member IEEE, Sze Mei 'Cat' Wong, Member IEEE, Maryclaire Peterson, Member IEEE, Peng $\mathrm{Yu}$, Member IEEE, Mukund R. Chander .. 2015. Relaybased Undervoltage load shedding scheme for Entergy's Western Region. Technical Studies (Transmission Planning),

[17] Kaffashan, I., Mortezaee, S.H. \& Amraee, T., 2016. A robust Undervoltage load shedding scheme against voltage instability. In 2016 Turk J Electr Eng Comput Sci. pp. 3310-3321.

[18] Jamroen, C., Piriyanont, B. \& Dechanupaprittha, S., 2017. Load shedding scheme based on voltage instability index using synchrophasor data. In 2017 International Electrical Engineering Congress (iEECON). pp. 1-4.

[19] Alzahawi, T., Sachdev, M.S. \& Ramakrishna, G., 2017. Time to voltage collapse dependence of load shedding to avoid voltage collapse. In 2017 IEEE Electrical Power and Energy Conference (EPEC). pp. 1-5.

[20] X. Xu, H. Zhang, C. Li, Y. Liu, W. Li, V. Terzija, Optimization of the Event-Driven Emergency LoadShedding Considering Transient Security and Stability Constraints, Electrical and Electronics Engineers (IEEE), vol. 32, Issue: 4, 31 October 2016, pp. 2581-2592

[21] Sayyed Mohammad Hashemi, Majid Sanaye-Pasand, Moein Abedini, 2019 Under-impedance load shedding: a new preventive action against voltage instability. School of Electrical and Computer Engineering, University of Tehran, Tehran, Iran. E-mail: msanaye@ut.ac.ir. IET Generation, Transmission \& Distribution 